\title{
The Randolph Glacier Inventory: a globally complete inventory of glaciers
}

\author{
W. Tad PFEFFER, ${ }^{1}$ Anthony A. ARENDT, ${ }^{2}$ Andrew BLISS, ${ }^{2}$ Tobias BOLCH, ${ }^{3,4}$
}

J. Graham COGLEY, ${ }^{5}$ Alex S. GARDNER, ${ }^{6}$ Jon-Ove HAGEN, ${ }^{7}$ Regine HOCK, ${ }^{2,8}$ Georg KASER, ${ }^{9}$ Christian KIENHOLZ, ${ }^{2}$ Evan S. MILES, ${ }^{10}$ Geir MOHOLDT, ${ }^{11}$ Nico MÖLG, ${ }^{3}$ Frank PAUL, ${ }^{3}$ Valentina RADIĆ, ${ }^{12}$ Philipp RASTNER, ${ }^{3}$ Bruce H. RAUP, ${ }^{13}$ Justin $\mathrm{RICH}^{2}$ Martin J. SHARP, ${ }^{14}$ THE RANDOLPH CONSORTIUM ${ }^{15}$

${ }^{1}$ Institute of Arctic and Alpine Research, University of Colorado, Boulder, CO, USA

${ }^{2}$ Geophysical Institute, University of Alaska Fairbanks, Fairbanks, AK, USA

${ }^{3}$ Department of Geography, University of Zürich, Zürich, Switzerland

${ }^{4}$ Institute for Cartography, Technische Universität Dresden, Dresden, Germany

${ }^{5}$ Department of Geography, Trent University, Peterborough, Ontario, Canada E-mail: gcogley@trentu.ca

${ }^{6}$ Graduate School of Geography, Clark University, Worcester, MA, USA

${ }^{7}$ Department of Geosciences, University of Oslo, Oslo, Norway

${ }^{8}$ Department of Earth Sciences, Uppsala University, Uppsala, Sweden

${ }^{9}$ Institute of Meteorology and Geophysics, University of Innsbruck, Innsbruck, Austria

${ }^{10}$ Scott Polar Research Institute, University of Cambridge, Cambridge, UK

${ }^{11}$ Institute of Geophysics and Planetary Physics, Scripps Institution of Oceanography, University of California, San Diego, La Jolla, CA, USA

${ }^{12}$ Department of Earth, Ocean and Atmospheric Sciences, University of British Columbia, Vancouver, British Columbia, Canada

${ }^{13}$ National Snow and Ice Data Center, University of Colorado, Boulder, CO, USA

${ }^{14}$ Department of Earth and Atmospheric Sciences, University of Alberta, Edmonton, Alberta, Canada

${ }^{15}$ A complete list of Consortium authors is in the Appendix

\begin{abstract}
The Randolph Glacier Inventory (RGI) is a globally complete collection of digital outlines of glaciers, excluding the ice sheets, developed to meet the needs of the Fifth Assessment of the Intergovernmental Panel on Climate Change for estimates of past and future mass balance. The RGI was created with limited resources in a short period. Priority was given to completeness of coverage, but a limited, uniform set of attributes is attached to each of the $\sim 198000$ glaciers in its latest version, 3.2. Satellite imagery from 1999-2010 provided most of the outlines. Their total extent is estimated as $726800 \pm 34000 \mathrm{~km}^{2}$. The uncertainty, about $\pm 5 \%$, is derived from careful single-glacier and basin-scale uncertainty estimates and comparisons with inventories that were not sources for the RGI. The main contributors to uncertainty are probably misinterpretation of seasonal snow cover and debris cover. These errors appear not to be normally distributed, and quantifying them reliably is an unsolved problem. Combined with digital elevation models, the RGI glacier outlines yield hypsometries that can be combined with atmospheric data or model outputs for analysis of the impacts of climatic change on glaciers. The RGI has already proved its value in the generation of significantly improved aggregate estimates of glacier mass changes and total volume, and thus actual and potential contributions to sea-level rise.
\end{abstract}

KEYWORDS: Antarctic glaciology, Arctic glaciology, glacier delineation, glacier mapping, remote sensing, tropical glaciology

\section{INTRODUCTION}

The Randolph Glacier Inventory (RGI) is a collection of digital outlines of the world's glaciers, excluding the Greenland and Antarctic ice sheets. The RGI was developed in a short (1-2 year) period with limited resources in order to meet the needs of the Fifth Assessment Report (AR5) of the Intergovernmental Panel on Climate Change (IPCC) for estimates of recent and future glacier mass balance. Priority was given to complete coverage rather than to extensive documentary detail. The rationale of the RGI (Casey, 2003; Cogley, 2009a; Ohmura, 2009) is that fewer attributes and, if unavoidable, locally reduced accuracy of delineation (Section 3) would be a price worth paying for the complete coverage that is essential for global-scale assessments. However, of the few attributes attached to each RGI vector outline, some are analytically valuable. For example the terminus-type attribute and the complete coverage combine to yield the first estimate of the global proportion of tidewater glaciers.

Complete coverage is desirable for a broad range of global-scale investigations. Volume-area scaling (e.g. Bahr and others, 1997) and other procedures to derive glacier volume (e.g. Farinotti and others, 2009; Linsbauer and others, 2012) require detailed knowledge of glacier areas, and in some cases a digital elevation model (DEM) as well. Glacier outlines are needed in geodetic estimation of 
volume changes by comparison of DEMs and altimetry, and of mass changes after the application of appropriate corrections (e.g. Berthier and others, 2010; Gardner and others, 2011). Glacier outlines are also crucial for the initialization of projections of glacier mass change (e.g. Gregory and Oerlemans, 1998; Bahr and others, 2009; Marzeion and others, 2012; Radić and others, 2014).

\subsection{History}

A global glacier inventory was first proposed, in the form of national lists of glaciers, during planning for the International Geophysical Year 1957-58. Progress was initially slow, but accelerated under the leadership of $F$. Müller during the 1970s, when the product became known as the World Glacier Inventory (WGI). The status of the WGI was assessed by the World Glacier Monitoring Service (WGMS, 1989). A digital version has been available since 1995 from the National Snow and Ice Data Center (NSIDC), Boulder, Colorado, USA (http://nsidc.org/data/glacier_inventory/). It combined the WGI with the Eurasian Glacier Inventory of Bedford and Haggerty (1996) but still covered only 25\% of the global glacierized area. The extended WGI-XF inventory of Cogley (2009a) increased the global coverage to $\sim 48 \%$. Incompleteness aside, the WGI and its variants do not include glacier outlines, making them difficult to use for the global assessment of glacier change. A different initiative was launched in 1995 as GLIMS (Global Land Ice Measurements from Space). GLIMS, led initially by H.H. Kieffer and later by J.S. Kargel, is a consortium of regional investigators contributing glacier outlines in a digital vector format (Raup and others, 2007; Kargel and others, in press). The GLIMS inventory, which has an extensive set of attributes, has grown steadily, but it too remains incomplete. In mid-2013, its coverage was $\sim 58 \%$ of global glacierized area, although it has multitemporal coverage of several thousand glaciers.

Thus, half a century of work has yielded only two globally complete digital depictions of glacier extent: GGHYDRO (Cogley, 2003), a raster product compiled in the early 1980s, and the vectors of the Digital Chart of the World (DCW) of Danko (1992). Like DCW, GGHYDRO is highly generalized, but it has been used in several global-scale assessments (e.g. Raper and Braithwaite, 2006; Hock and others, 2009; Radić and Hock, 2010). Other assessments (e.g. Meier and Bahr, 1996; Ohmura, 2004; Dyurgerov and Meier, 2005; Raper and Braithwaite, 2005) have relied on separate indirect estimates of global aggregate information. Not all assessments have included the peripheral glaciers around the two ice sheets.

In recognition of the importance of baseline information for the assessment of glacier changes, the idea of a complete inventory of the world's glaciers has been strongly endorsed by international organizations such as the World Meteorological Organization (2004).

Free access to the US Geological Survey's archive of Landsat imagery (Wulder and others, 2012) has both stimulated and facilitated the mapping of glacier extent at regional and broader scales. The failure of the scan-line corrector of Landsat 7's Enhanced Thematic Mapper Plus (ETM+) sensor in May 2003 (Markham and others, 2004) limited the subsequent usefulness of that archive, but other sensors have offered a further stimulus by making possible, by stereographic or interferometric mapping, the construction of DEMs and thus the subdivision of ice bodies along drainage divides and the calculation of topographic and hypsometric glacier attributes. These products include the Advanced Spaceborne Thermal Emission and Reflection Radiometer (ASTER) global DEM and the DEM of the Shuttle Radar Topography Mission of February 2000. Their advantages and disadvantages are discussed by Frey and Paul (2012). In addition, several collaborative international projects, such as GlobGlacier (Paul and others, 2009a) and Glaciers_cci (Paul and others, 2012), have facilitated inventory-related data collection and production. Finally, the most immediate stimulus for rapid assembly of the RG was the need for a globally complete inventory to meet the goals of the recently completed contribution of Working Group I to AR5 of the IPCC.

The RGI was planned by an ad hoc group that assembled four times between December 2010 and December 2011. One of the meeting venues, Randolph, New Hampshire, USA, gave its name to the resulting product. The members of the group pooled material already in their possession and approached other colleagues individually, and solicited additional contributions from the Cryolist (http://cryolist.org) and GLIMS communities and other sources. More than 60 colleagues from 18 countries contributed, making the RGI a truly global initiative.

\subsection{Distribution of the RGI}

The RGI is distributed through the GLIMS/NSIDC website (http://www.glims.org/RGl/randolph.html), and is accompanied by technical documentation (Arendt and others, 2013). To allow some contributors time to report their own results, access was initially granted on the understanding that the inventory be used only for purposes related to AR5. This constraint has now been removed. It is intended that in due course the RGI outlines will be merged into the GLIMS database. Planning of this merger is in progress (Raup and others, 2013).

The version described here, RGI 3.2, reflects the correction of topological, georeferencing and interpretative errors detected in RGI 1.0, released in February 2012, and RGI 2.0, released in June 2012, as well as the application of quality controls described in Section 2. Versions 3.0 and 3.1 were interim releases. Version 3.2 substitutes improved outlines in a number of regions, adds a small number of outlines from previously omitted regions, and features a uniform set of attributes (Section 2.4). Auxiliary information includes outlines of a set of 19 first-order and 89 second-order regions (see Section 2.3 and the Supplementary Information (http:// www.igsoc.org/hyperlink/13j176/13j176supp.pdf) which includes maps showing the second-order regions).

\section{METHODS AND QUALITY CONTROL}

\subsection{Glacier outline generation and data sources}

Parts of the RGI were compiled at several institutions, but the inventory was assembled in its entirety at the University of Alaska Fairbanks. The earliest version consisted of DCW outlines, which were then replaced by outlines from GLIMS where available. Further additions of new or replacement outlines from contributors were assimilated, checked and if necessary revised using standard vector-editing tools. All outlines were transformed when necessary to the World Geodetic System 1984 (WGS84) datum.

Most of the glacier outlines in the RGI with known dates were derived from satellite imagery acquired in 1999 or later. Various Landsat platforms, principally Landsat 5 TM 
and Landsat $7 \mathrm{ETM}+$, were the primary sources, and imagery from ASTER, IKONOS and SPOT 5 high-resolution stereo (HRS) sensors was also used. In northernmost Greenland, the RGI draws on the ice mask of the Greenland Mapping Project (Howat and others, 2014). For most regions automatic or semi-automatic routines were used to map glaciers based on the distinctive spectral reflectance signatures of snow and ice in simple and normalized band-ratio maps (e.g. Le Bris and others, 2011). Some outlines were produced by manual digitizing on satellite imagery or on scanned digital copies of maps.

Glacier complexes (unsubdivided ice bodies) were subdivided into glaciers either by visual identification of flow divides or with semi-automated algorithms for detection of divides in a DEM (Bolch and others, 2010; Kienholz and others, 2013). These algorithms use standard watershed delineation tools to build a preliminary map of ice 'flowsheds' which are then merged, based on chosen thresholds for the proximity of their termini, to form glaciers. The Bolch algorithm was applied in western Canada, parts of Alaska, Greenland and parts of High Mountain Asia. The Kienholz algorithm was developed, calibrated and qualitychecked in Alaska and Arctic Canada South, and was applied without quality assessment in several other regions, where errors due to subdivision will be governed primarily by the quality of the DEM.

Some of our source inventories have been published only recently, including Nuth and others (2013) for Svalbard, Rastner and others (2012) for Greenland, and Bliss and others (2013) for the Antarctic and Subantarctic. These three sources represent $5 \%, 12 \%$ and $18 \%$ of global glacier extent respectively. During assembly of the RGI, many GLIMS contributions of restricted extent were replaced by outlines from sources with more extensive coverage. However, the RGI outlines in British Columbia, the Caucasus and Iceland come entirely, and those in China mostly, from GLIMS, and there are also limited contributions in Central Asia and Alaska. GLIMS has therefore contributed at least $10 \%$ of the RGI coverage. The RGI still draws on the DCW for $\sim 1 \%$ of global ice extent in northern Afghanistan, Tajikistan and Kyrgyzstan. In the Pyrenees, Iran and parts of North and Central Asia, the RGI records 'nominal glaciers' for which only location and area are available. They are represented by circles of the area reported in the WGI or WGI-XF, and account for $<0.3 \%$ of global glacierized area. One glacierized region, Chukotka in easternmost Russia, does not appear in the RGI because the locations of its $\sim 17 \mathrm{~km}^{2}$ of glaciers (Sedov, 1997) were unobtainable.

\subsection{Outline geometry and topology}

Each object in the RGI conforms to the data-model conventions of ESRI ArcGIS shapefiles. That is, each object consists of an outline encompassing the glacier, followed immediately by outlines representing all of its nunataks (icefree areas enclosed by the glacier). This data model is not the same as the GLIMS data model, in which nunataks are independent objects.

Each component polygon of the RGl object is tested for closure, i.e. its last vertex is tested for identity with its first vertex. Polygons that are degenerate (having fewer than three distinct vertices) are removed. ArcGIS's Repair Geometry tool is used to check correct ordering of points within each polygon. Overlapping polygons and small unassigned 'sliver' areas are corrected iteratively; they commonly result
Table 1. Glacier attributes in the Randolph Glacier Inventory. Further details are provided at http://www.igsoc.org/hyperlink/ 13j176/13j176supp.pdf

\begin{tabular}{|c|c|c|}
\hline Attribute & Format & Content \\
\hline RGIld & character & Identifier (unique within each RGI version) \\
\hline GLIMSId & character & Identifier (GLIMS format) \\
\hline RGIFlag & character & Qualifiers of glacier eligibility \\
\hline BgnDate & YYYYMMDD & Date of outline, or first date of a range \\
\hline EndDate & YYYYMMDD & End date of a range \\
\hline CenLon & numeric & Longitude of glacier centroid $\left(^{\circ}\right)$ \\
\hline CenLat & numeric & Latitude of glacier centroid $\left(^{\circ}\right)$ \\
\hline O1Region & character & First-order region number (Table S1) \\
\hline O2Region & character & Second-order region number (Table S1) \\
\hline Area & numeric & Area of glacier $\left(\mathrm{km}^{2}\right)$ \\
\hline GlacType & character & Terminus-type code \\
\hline Name & character & Name of glacier \\
\hline
\end{tabular}

from the alteration of a glacier divide in only one of its two polygons. Scripts to run many of our topology checks are available at https://github.com/AGIScripts/script_glaciers.

Glaciers with areas less than $0.01 \mathrm{~km}^{2}$, the recommended minimum of the WGI, are removed. However, some of the source inventories had larger minimum-area thresholds, so not all regions include glaciers down to the $0.01 \mathrm{~km}^{2}$ threshold (Section 4.1). Nunataks are retained whatever their area. Glaciers contained within nunataks are recognized as independent ice bodies.

\subsection{Regionalization}

In regional or global studies it is convenient to group glaciers by proximity. Several different bases for regionalization can be imagined, such as grouping by climatological, hydrographic or topographic commonalities. However, no one scheme can serve all of the purposes for which a global glacier inventory might be used, and the RGI regions (Fig. 1) were developed under only three constraints: that they should resemble commonly recognized glacier domains, that together they should contain all of the world's glaciers, and that their boundaries should be simple and readily recognizable on a map of the world.

There are 19 first-order regions, derived from the regions of Radić and Hock (2010) and modified in relatively minor ways. The first-order regions are subdivided into 89 secondorder regions (http://www.igsoc.org/hyperlink/13j176/ 13j176supp.pdf: Table S1; Figs S1-S19). Most of the regional boundary segments follow parallels and meridians, but some adjacent regions are separated topographically along drainage divides. Widespread and consistent use of the RGI regions is encouraged as a way of facilitating comparisons between studies.

\subsection{Attributes}

The RGI attaches 12 attributes, offering basic locational and identifying information, to each glacier (Tables 1 and S2). Each glacier has a unique RGIld code, a GLIMSId code (Raup and Khalsa, 2007) and, where it exists and is readily available, a Name. The RGIFlag attribute warns whether the glacier is a nominal glacier (Section 2.1) or a glacier complex (not yet subdivided from its neighbours, if any; this label appears only for 80 glaciers in the Low Latitudes). In Greenland, RGIFlag indicates which of three 'connectivity levels' (Rastner and others, 2012) the glacier belongs to 


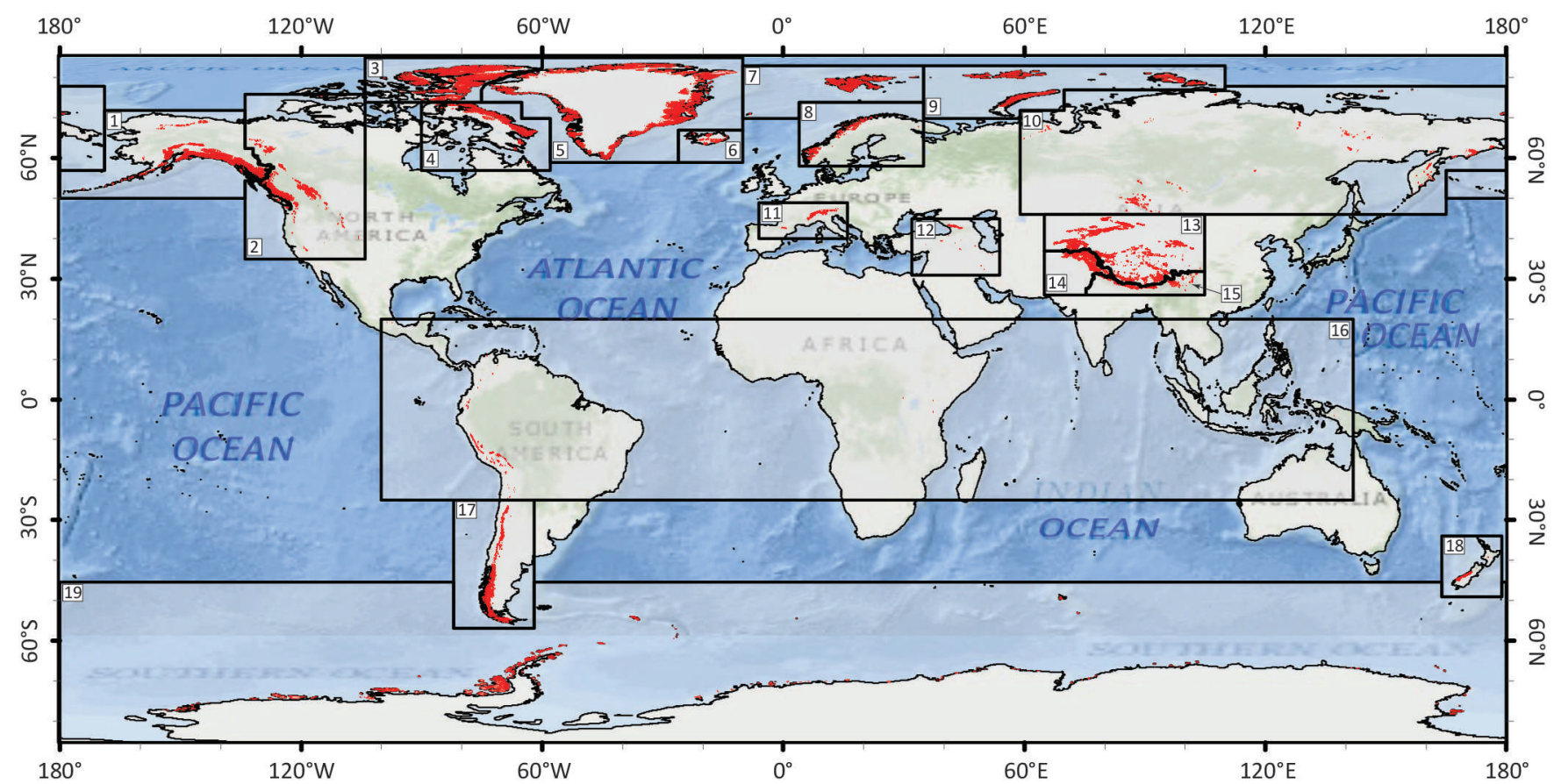

Fig. 1. First-order regions of the RGI, with glaciers shown in red. Region numbers are those of Table 2. Cylindrical equidistant projection.

(Section 4.2), and in the Antarctic and Subantarctic, but not yet in other regions, it distinguishes between glaciers and ice caps. The GlacType attribute implements table 1 of Paul and others (2009b), although only the terminus-type code is assigned values (land-, marine-, lake- or shelf-terminating) in RGI 3.2. As yet, lake-terminating glaciers have been distinguished from land-terminating glaciers only in Alaska, the Southern Andes and Antarctica. First- and second-order region numbers are given by O1Region and O2Region. A more precise location is given by the longitude CenLon and latitude CenLat of the glacier; these attributes also appear in GLIMSId. Most of the locations are centroids of glacier polygons; $\sim 1 \%$ lie outside their polygons. The glacier area is

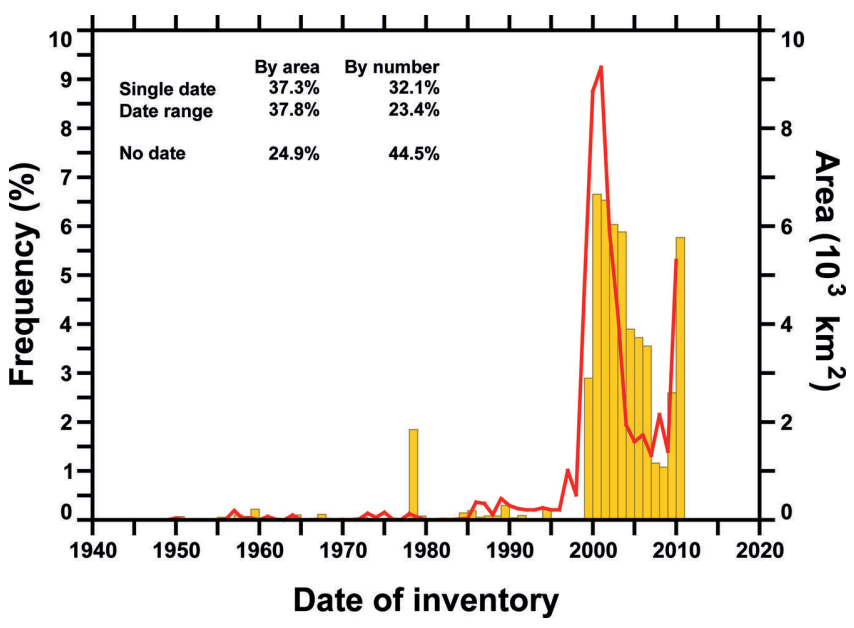

Fig. 2. Frequency distribution of known dates and date ranges in the RGI by glacierized area (red line) and glacier number (yellow histogram). Glaciers with date ranges are assigned with uniform probability to each year of the range. Undated glaciers are not represented. Those in China date from the 1970s and 1980s and in Antarctica from the 1960s to 2000s. Most other undated glaciers are known to have been measured on Landsat ETM+, ASTER or SPOT5 imagery, i.e. of the late 1990 s or later. given by Area, which is calculated in Cartesian coordinates on a cylindrical equal-area projection of the authalic sphere of the WGS84 ellipsoid, or, for nominal glaciers, is accepted from the source inventory. The date of the source (Fig. 2) is given by BgnDate if it is known, or by a range BgnDate, EndDate. About $45 \%$ of the glaciers by number, accounting for $\sim 25 \%$ of global glacierized area, lack date information.

\section{ACCURACY}

\subsection{Data quality}

Accurate recognition of glaciers in satellite imagery can be challenging (Paul and others, 2013). Maps can be similarly difficult to work with, and sometimes offer additional difficulties such as poor georeferencing and inadequate datum information. The accuracy of the result depends on the resolution and quality of the source imagery or map, the scale at which the analyst traces the glacier outlines, and his or her skill at identifying glacier surfaces consistently (e.g. Bhambri and Bolch, 2009).

The glacier outlines in Figure 3 are from RGI 3.2 and are superimposed on Google Earth images. In each panel the outlines are of inadequate quality and need substantial reworking. Those in Figure $3 a$ are at the correct locations, but many are too large by $>50 \%$. The outlines include icefree glacier forefields, mountain rock walls, and rock glaciers. The outlines in Figure $3 \mathrm{~b}$ are rather precise on the east side of the image and north of the drainage divide, but glaciers south of it and in the west are either missing, represented by nominal circles from the WGI, or digitized in a highly generalized way. In Figure $3 c$ the outlines show some generalization, with missing nunataks, but the largest problem is the wrong geolocation. There is a systematic shift of all outlines relative to the satellite image in the background (which also shows seasonal snow cover, a potential cause of misinterpretation). Figure $3 \mathrm{~d}$ illustrates the omission of many glaciers, and also outlines that are wrongly placed and highly generalized. 

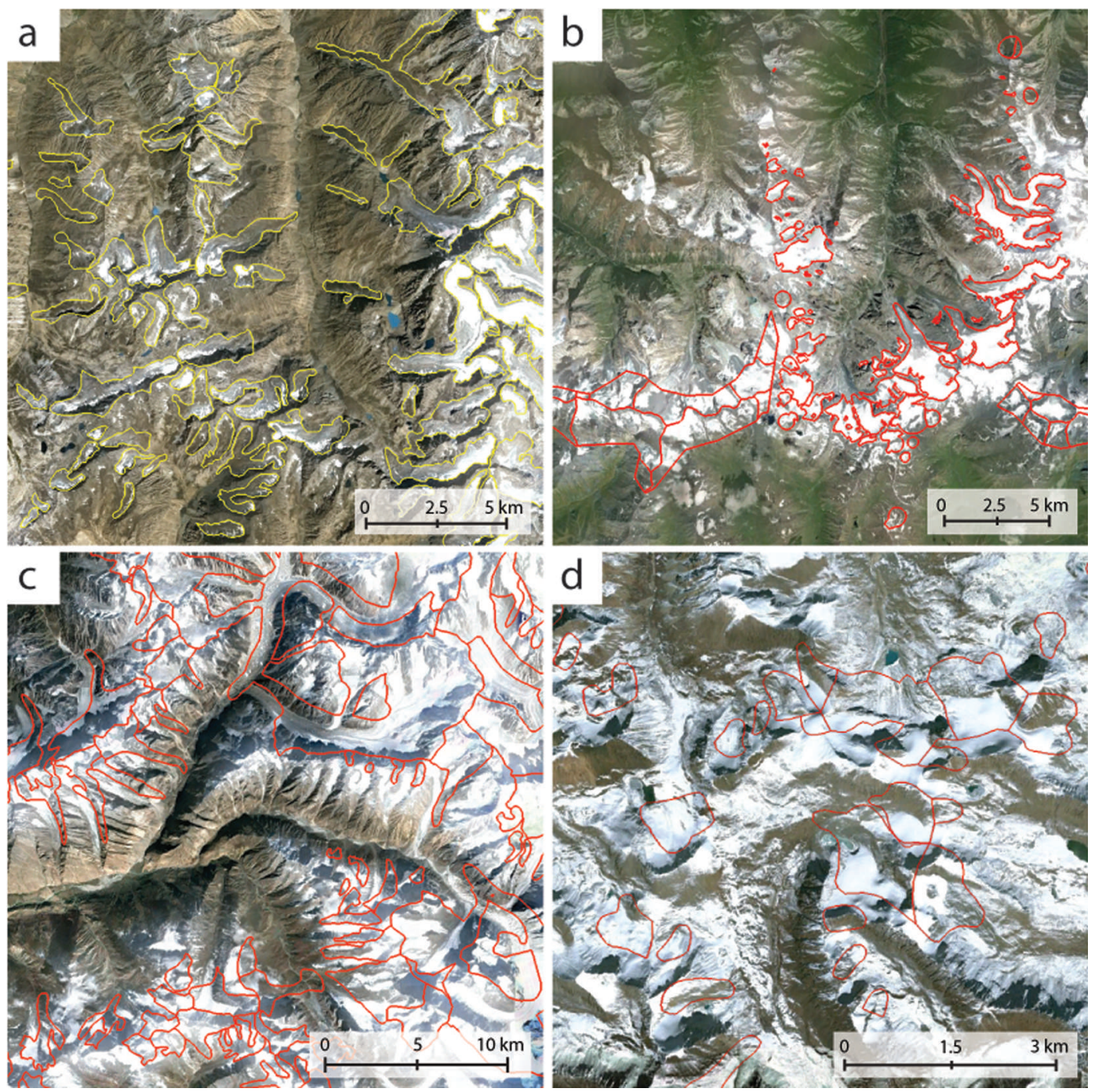

Fig. 3. Images illustrating difficulties in the estimation of glacierized area for four regions in High Mountain Asia: (a) Hindu Kush, (b) northern Tien Shan, (c) Karakoram and (d) eastern Nyainqentanglha. All outlines are overlaid on Google Earth satellite images.

The problems illustrated here are addressed in Sections 3.2 and 3.3. Mislocated outlines have only limited effect on measurements of glacier area, but can introduce serious errors into procedures that rely on absolute positioning (e.g. co-registration to other datasets such as DEMs). Unless mislocations can be traced to systematic (and correctable) errors (e.g. due to misprojection or to errors in datum transformations), the only realistic way to correct them is to supply more accurate outlines. One highly anticipated source of improved outlines is the second Chinese Glacier Inventory.

\subsection{An error model}

Because the sources of the RGI outlines are so diverse, it is not practical to estimate uncertainties source by source. Instead, we develop a simple model of uncertainty in glacier area, drawing on published estimates that have uncertainties attached. Small areas are harder to measure accurately than large areas (Fig. 4) because the measurement error tends to be inversely proportional to the length of the glacier margin. Estimates for collections of glaciers would ideally be calculated by summing the errors of glacier complexes rather than those of individual glaciers, because errors at flow divides sum to zero when both sides of the divide are included. However, Figure 4 shows no clear difference between single-glacier and multiple-glacier errors. We fit a power law by least squares to the relationship between fractional uncertainty and glacier area and assume as a first guess that this captures the contributions of inaccurate treatment of debris cover, omission of nunataks, inclusion of seasonal snow, and inaccurate mapping. This yields the relation

$$
e(s)=k e_{1} s^{p}
$$

between the error $e$ and area $s$ (both in $\mathrm{km}^{2}$ ); $p$ is 0.70 , and $e_{1}=0.039$ is the estimated fractional error in a measured area of $1 \mathrm{~km}^{2}$. The correction factor $k$ is discussed in Section 3.3 . For each glacier in the RGI, the standard error is the arithmetic sum of $e(s)$ as calculated for the glacier and all of its nunataks. Regional uncertainties presented below are also simple sums of all single-glacier area errors, which we expect, consistent with the simple reasoning that leads to Eqn (1), to be fully correlated.

\subsection{A case study: South America}

In earlier versions of the RGI, various factors obliged us to select satellite images of South America that in some cases showed extensive seasonal snow. Because it is timeconsuming, the visual inspection needed to correct automatically generated outlines for the seasonal snow was not always possible. In RGI 3.2 we have corrected much of the resulting overestimate of glacier area by identifying images 


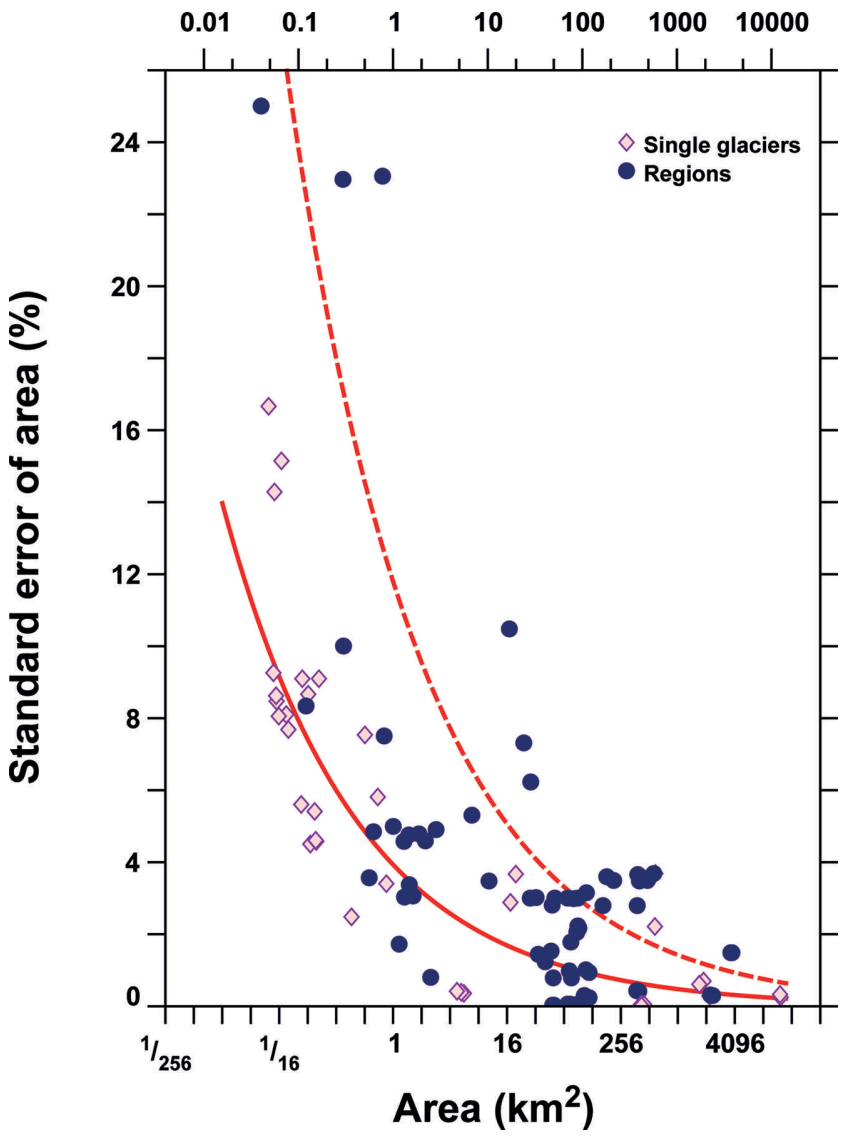

Fig. 4. Published estimates of the uncertainty of area measurements of single glaciers (diamonds) and collections of glaciers (dots). See http://www.igsoc.org/hyperlink/13j176/13j176supp.pdf for a list of sources. Solid line: best-fitting relationship between measured area and its standard error from Eqn (1) in text (with $k=1$ ). Dashed line: relationship adopted for estimation of RGI errors (from Eqn (1) with $k=3$ )

of better quality, but because seasonal snow was apparent in all available images our estimated ice cover in South America, $31670 \mathrm{~km}^{2}$, may still be too large. There is no authoritative estimate for comparison; WGMS (1989) gives estimates for the South American nations which sum to $25900 \mathrm{~km}^{2}$, but they are mostly undated and all involve some guesswork for unsurveyed regions.

We therefore assembled repeated measurements of the glacierized area of 37 South American subregions from the literature and compared them to corresponding sums of areas of RGI glaciers (Fig. 5). Where possible, we interpolated linearly from the bracketing dates of the independently measured areas from the literature to the date of the RGI image covering the subregion; where necessary, we extrapolated linearly, by from 0.5 to 9 years. (See www.igsoc.org/ hyperlink/13j176/13j176supp.pdf for references.)

In five subregions where there are multiple independent measurements, the measurements differ, with standard deviations ranging from $1.2 \%$ to as great as $38 \%$. After averaging these multiple measurements, the deviations $\Delta=\left(S-S_{\text {ind }}\right) / S_{\text {ind }}$ between RGI areas $S$ and independent areas $S_{\text {ind }}$ range from $-68 \%\left(-63 \mathrm{~km}^{2}\right)$ to $+149 \%\left(+150 \mathrm{~km}^{2}\right)$. The RGI total, $25842 \mathrm{~km}^{2}$, is $5.4 \%$ greater than the independent total, $24506 \mathrm{~km}^{2}$, and the mean and median of the absolute deviations $|\Delta|$ are $30 \%$ and $13 \%$ respectively.

We conclude that area errors of tens of percent or more are possible in either or both of the RGI and the independent areas. Equation (1) (with $k=1$ ) probably represents the best case, in which researchers have estimated uncertainties explicitly, although in a variety of ways. We are aware of further biases, due to one or more of the problems illustrated in Figure 3, in regions other than South America. For example, Gardelle and others (2013) found an average discrepancy in area of only $-1.1 \%$ between RGI 2.0 and seven of their eight SPOT 5 scenes in South Asia, but in the eighth, in southeastern Tibet, RGI 2.0 has an extent $88 \%$ greater than their estimate. Many RGI contributions, notably in Alaska, Arctic Canada North and South, Greenland, Svalbard, the Russian Arctic, Central Europe and parts of South Asia West, are significantly more accurate than such worst-case examples. However, for the RGI as a whole we do not know how strongly the probability distribution of the errors is skewed by gross errors, so it seems prudent to scale Eqn (1), which captures an important part of the error structure, to reflect the likely non-normality of the error distribution. The sample of errors in Figure 4 and the sample of differences in Figure 5 both fail tests for goodness of fit to the normal distribution. Departures from normality are not surprising if we consider the difficulty of correcting for erratically variable seasonal snow, and equivalently the difficulty of recognizing debris-covered ice. It is also true that widely variable methods reduce the comparability of uncertainties estimated by different analysts.

How to correct Eqn (1) is not obvious, because the main sources of uncertainty, being heterogeneous across regions and data sources, are not amenable to handling with conventional statistics. Moreover, although Figure 5 suggests that Eqn (1) is likely to underestimate the uncertainty, a further consideration is that we have applied Eqn (1) to glaciers, rather than to glacier complexes as would be preferable because of the cancellation of errors at divides; a test calculation based on glacier complexes in the Russian Arctic yielded an area error of only $\pm 1.2 \%$ as against $\pm 2.8 \%$ for glaciers. As an interim measure pending further investigation, we set the correction factor $k$ in Eqn (1) to 3 (a number chosen arbitrarily).

\section{RESULTS AND APPLICATIONS OF THE INVENTORY}

\subsection{Glacier numbers}

The RGI contains outlines for $\sim 198000$ glaciers. We stress that the total number of glaciers in the world, or in any region, is an arbitrary quantity. The fineness of subdivision of glacier complexes into glaciers varies from region to region, influenced by particular objectives and available resources. For example, glacier complexes in the Antarctic are subdivided less finely than elsewhere. Moreover, subdivision of ice bodies can produce doubtful results when the best available DEM or map is poor; glaciers tend to fragment in a warming climate; and the total number is strongly determined by the choice of minimum-area threshold (Bahr and Radić, 2012).

The spatial resolution of the source image or map will impose a minimum-area threshold for the identification of glaciers, but the choice of threshold is also influenced by the availability of resources. The labour needed for manual digitizing or for visual correction of automatically obtained outlines increases dramatically as the area threshold is reduced, and the time available for compiling a typical regional inventory can easily be overwhelmed by large numbers of 


$10^{\circ} \mathrm{N}$ Santa Marta
$08^{\circ} \mathrm{N}$ S Nevada de Merida
$06^{\circ} \mathrm{N}$ El Cocuy
$04^{\circ} \mathrm{N}$ Nevado Santa Isabel
$04^{\circ} \mathrm{N}$ Nevado del Ruiz
$04^{\circ} \mathrm{N}$ Nevado del Tolima
$02^{\circ} \mathrm{N}$ Nevado del Huila
$01^{\circ} \mathrm{S}$ Cotopaxi
$10^{\circ} \mathrm{S}$ Cordillera Blanca
$14^{\circ} \mathrm{S}$ Cordillera Vilcanota
$16^{\circ} \mathrm{S}$ Nevado Coropuna
$17^{\circ} \mathrm{S}$ Cordillera Tres Cruces
$29^{\circ} \mathrm{S}$ R Huasco
$33^{\circ} \mathrm{S}$ R Aconcagua
$40^{\circ} \mathrm{S}$ V Mocho Choshuenco
$42^{\circ} \mathrm{S}$ Mt Tronador
$43^{\circ} \mathrm{S}$ Hornopiren
$43^{\circ} \mathrm{S}$ Minchinmavida
$44^{\circ} \mathrm{S}$ Corcovado National Park
$45^{\circ} \mathrm{S}$ Queulat National Park
$47^{\circ} \mathrm{S}$ Mt Hudson
$47^{\circ} \mathrm{S}$ Mt Erasmo
$48^{\circ} \mathrm{S}$ Mt San Lorenzo
$48^{\circ} \mathrm{S} \mathrm{N}$ Patagonian IF and environs
$48^{\circ} \mathrm{S}$ El Volcan
$48^{\circ} \mathrm{S}$ S Patagonian IF and environs
$49^{\circ} \mathrm{S}$ Sierra de Sangra
$53^{\circ} \mathrm{S}$ Mt Burney
$53^{\circ} \mathrm{S}$ Peninsula Munoz Gamero
$54^{\circ} \mathrm{S}$ Isla Riesco
$54^{\circ} \mathrm{S} \mathrm{C}$ Isla Santa Ines
$55^{\circ} \mathrm{S}$ Mt Sarmiento
$55^{\circ} \mathrm{S}$ W Cordillera Darwin
$55^{\circ} \mathrm{S}$ Cordillera Darwin
$56^{\circ} \mathrm{S}$ W Isla Hoste

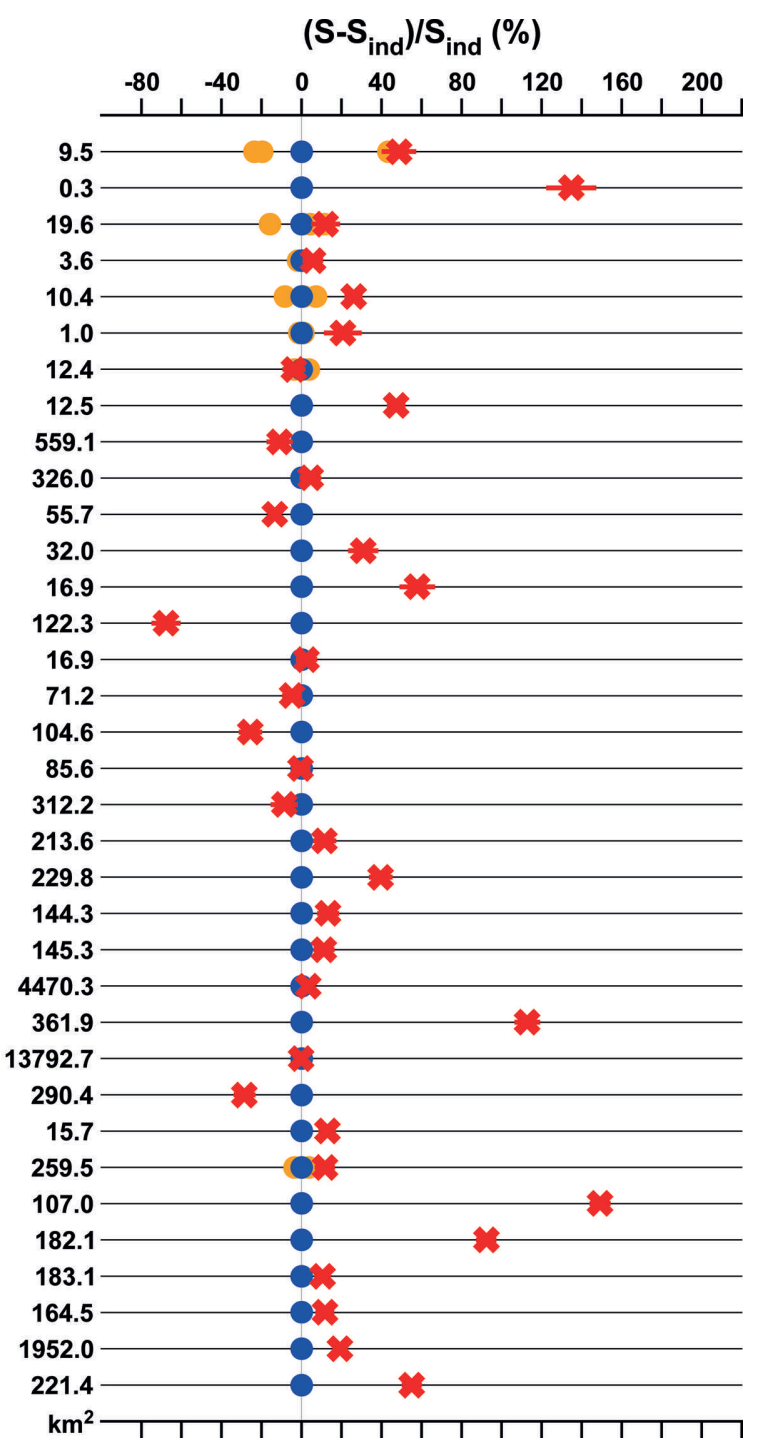

Fig. 5. A comparison of RGl glacierized areas $S$ for subregions in South America with equivalent measurements $S_{\text {ind }}$ from independent studies (listed at http://www.igsoc.org/hyperlink/13j176/13j176supp.pdf). The subregions, their approximate latitudes and independently obtained glacierized areas $\left(\mathrm{km}^{2}\right)$ are listed at left. Orange dots: independent measurements (up to three per region); blue dots: averages of independent measurements (as listed at left, but uniformly zero in the graph); red crosses: RGI measurements (horizontal error bars are smaller than symbol size for most subregions).

very small glaciers. For example, in their glacier inventory of British Columbia (not part of the RGI), Schiefer and others (2008) adopted a threshold of $0.1 \mathrm{~km}^{2}$ and an additional threshold based on glacier elevation ranges. By comparisons to subregional inventories with lower thresholds, they estimated that their thresholds excluded $\sim 69 \%$ of the actual glaciers by number, but only $\sim 7 \%$ of total glacierized area. In Section 4.2 we discuss the impact of omission of glaciers on the RGI estimates of glacier numbers and areas.

\subsection{Glacier areas}

The total glacierized area in the RGI is $726800 \mathrm{~km}^{2}$ (Table 2). The region with the most ice is the Antarctic and Subantarctic $\left(132900 \mathrm{~km}^{2}\right)$, followed by Arctic Canada North with $104900 \mathrm{~km}^{2}$. The regions with the least ice are the Caucasus and Middle East $\left(1140 \mathrm{~km}^{2}\right)$ and New Zealand $\left(1160 \mathrm{~km}^{2}\right)$. Of the total extent, $44 \%$ is in the Arctic regions (Arctic Canada North, Arctic Canada South, Greenland, Svalbard and Russian Arctic) and 18\% in the Antarctic and Subantarctic. High Mountain Asia (i.e. Central Asia, South Asia West and South Asia East) accounts for $16 \%$ and Alaska for $12 \%$. The uncertainty in total regional area depends on the distribution of glacier areas, which we discuss below. According to Eqn (1), regional uncertainty is as small as $\pm 1.9 \%$ in the Antarctic and Subantarctic, where Bliss and others (2013) assumed an uncertainty of $\pm 5 \%$, and exceeds $\pm 10 \%$ in five regions with relatively small glaciers.

The total ice-covered area in RGI 3.2 is similar to earlier estimates (Table 3). Excluding Greenland and Antarctica, the largest deviation from the RGI in Table 3 is $+7 \%$ (the areas determined by Meier and Bahr (1996) and Dyurgerov and Meier (2005)), consistent with an uncertainty of the order of $\pm 3.5 \%$. The analysis in Section 3, however, suggests a somewhat greater uncertainty. The RGI area is the smallest of the entries. This is partly because some of the earlier estimates include $6000-8000 \mathrm{~km}^{2}$ of ice in the Subantarctic, which in the RGI is included in the Antarctic and Subantarctic region and thus excluded from this column of the table. Glacier shrinkage between older and newer sources of regional information may also account for some of the difference. When the Greenland and Antarctic glaciers are included, earlier estimates differ from the RGI 
Table 2. Summary of the RGI, Version 3.2

\begin{tabular}{|c|c|c|c|c|c|c|}
\hline \multirow{3}{*}{ Region } & \multicolumn{3}{|c|}{ All glaciers } & \multirow{3}{*}{$\begin{array}{c}\text { Tidewater glaciers } \\
\text { Area } \\
\mathrm{km}^{2}\end{array}$} & \multicolumn{2}{|c|}{ Nominal glaciers } \\
\hline & Number & Area & Error* & & Number & Area \\
\hline & & $\mathrm{km}^{2}$ & $\%$ & & & $\mathrm{~km}^{2}$ \\
\hline 01 Alaska & 26944 & 86715 & 5.3 & 11781 & 0 & 0 \\
\hline 02 Western Canada and US & 15215 & 14559 & 9.5 & 0 & 0 & 0 \\
\hline 03 Arctic Canada North & 4538 & 104873 & 3.2 & 49111 & 0 & 0 \\
\hline 04 Arctic Canada South & 7347 & 40894 & 4.9 & 3030 & 0 & 0 \\
\hline 05 Greenland Periphery & 19323 & 89721 & 5.0 & 31106 & 0 & 0 \\
\hline 06 Iceland & 568 & 11060 & 2.6 & 0 & 0 & 0 \\
\hline 07 Svalbard and Jan Mayen & 1615 & 33922 & 3.5 & 14884 & 0 & 0 \\
\hline 08 Scandinavia & 2668 & 2851 & 9.3 & 0 & 4 & $<1$ \\
\hline 09 Russian Arctic & 1069 & 51592 & 2.8 & 33435 & 0 & 0 \\
\hline 10 North Asia & 4403 & 3430 & 10.3 & 0 & 2832 & 1868 \\
\hline 11 Central Europe & 3920 & 2063 & 10.4 & 0 & 108 & 11 \\
\hline 13 Central Asia & 46543 & 62606 & 8.4 & 0 & 25 & 24 \\
\hline 14 South Asia West & 22822 & 33859 & 7.7 & 0 & 0 & 0 \\
\hline 15 South Asia East & 14095 & 21799 & 8.3 & 0 & 0 & 0 \\
\hline 16 Low Latitudes & 2863 & 2346 & 10.5 & 0 & 0 & 0 \\
\hline 17 Southern Andes & 16046 & 29333 & 5.9 & 7004 & 0 & 0 \\
\hline 18 New Zealand & 3537 & 1162 & 12.2 & 0 & 0 & 0 \\
\hline 19 Antarctic and Subantarctic & 2752 & 132867 & 1.9 & 131192 & 0 & 0 \\
\hline 00 Total & 197654 & 726792 & 4.7 & 281543 & 3006 & 1930 \\
\hline
\end{tabular}

*Errors from Eqn (1) (with $k=3$ ).

by as much as $-6 \%$ and $+8 \%$. These differences mainly reflect substantial improvement in the sources of information. Rastner and others (2012) identified considerably more peripheral ice in Greenland than most previous investigations, and Bliss and others (2013) relied mainly on the Antarctic Digital Database (ADD Consortium, 2000), a more accurate source than those of earlier estimates.

Tidewater glaciers account for $39 \%$ of the total RGI extent. This statistic, reported earlier by Gardner and others (2013) using RGI 3.0, is valuable because it is the first entirely measurement-based estimate of the potential importance of tidewater glaciers among the world's glaciers. It appears to confirm that the under-representation of calving glaciers and frontal ablation in mass-balance measurement programmes is more serious than calculated by Cogley (2009b), in whose dataset only $3 \%$ by area of the glaciers with glaciological measurements were tidewater glaciers. Including glaciers with geodetic measurements, the proportion rose to $16 \%$, still well below the new RGI estimate.

In contrast to ice-sheet modelling, most modelling of glacier mass balance necessarily focuses on the climatic

Table 3. Published estimates of total glacierized area $\left(10^{3} \mathrm{~km}^{2}\right)$

\begin{tabular}{lcc}
\hline Source & Excl* & Incl $^{\dagger}$ \\
\hline Meier and Bahr (1996) & 540 & 680 \\
Ohmura (2004) & 521 & \\
Dyurgerov and Meier (2005) & $540 \pm 30$ & $785 \pm 100$ \\
Raper and Braithwaite (2005) & 522 & \\
Hock and others (2009) & & $704 \pm 56$ \\
Radić and Hock (2010) & $518 \pm 7$ & $741 \pm 68$ \\
RGl 3.2 & $504 \pm 27$ & $727 \pm 34$ \\
\end{tabular}

*Excluding Greenland and Antarctica.

Including Greenland and Antarctica. mass balance because the modelling of frontal losses due to dynamics is relatively underdeveloped, and more seriously because basic information required for the assessment of possible rapid dynamic responses of tidewater glaciers is only starting to be collected. Concrete evidence of rapid dynamic response is provided by Burgess and others (2013) for Alaska, where only $14 \%$ of the region's glacier area is drained through tidewater outlets, but calving accounts for $36 \%$ of the regional loss rate. We expect that improved estimates of the extent of tidewater glaciers will aid in the determination of dynamical mass losses.

The proximity of glaciers in Greenland and Antarctica to the ice sheets requires care to avoid double-counting or omission by different groups working on large-scale cryospheric analyses. For example, gravimetric measurements of mass change by the Gravity Recovery and Climate Experiment (GRACE) satellites have low spatial resolution and are unable to distinguish the peripheral glaciers from the ice sheets. In Antarctica the implications of proximity are reduced, but not eliminated, because the RGI excludes the mainland. In Greenland the RGI includes all the peripheral glaciers, each of which is assigned a connectivity level CL (through RGIFlag; see Table S2 (http:// www.igsoc.org/hyperlink/13j176/13j176supp.pdf)). The three values of $C L$ represent glaciers that are unconnected, weakly connected or strongly connected to the ice sheet; the basis and methodology for these assignments are explained by Rastner and others (2012). We follow their suggestion that the strongly connected CL2 glaciers, with an extent of $40400 \mathrm{~km}^{2}$, be regarded as part of the Greenland ice sheet, yielding an area of $1718000 \mathrm{~km}^{2}$ for the ice sheet including the CL2 glaciers. (The CL2 glaciers are nevertheless included in the RGI shapefile for Greenland.) The areas of the CLO (unconnected; $65500 \mathrm{~km}^{2}$ ) and CL1 (weakly connected; $24200 \mathrm{~km}^{2}$ ) glaciers sum to $89700 \mathrm{~km}^{2}$. 


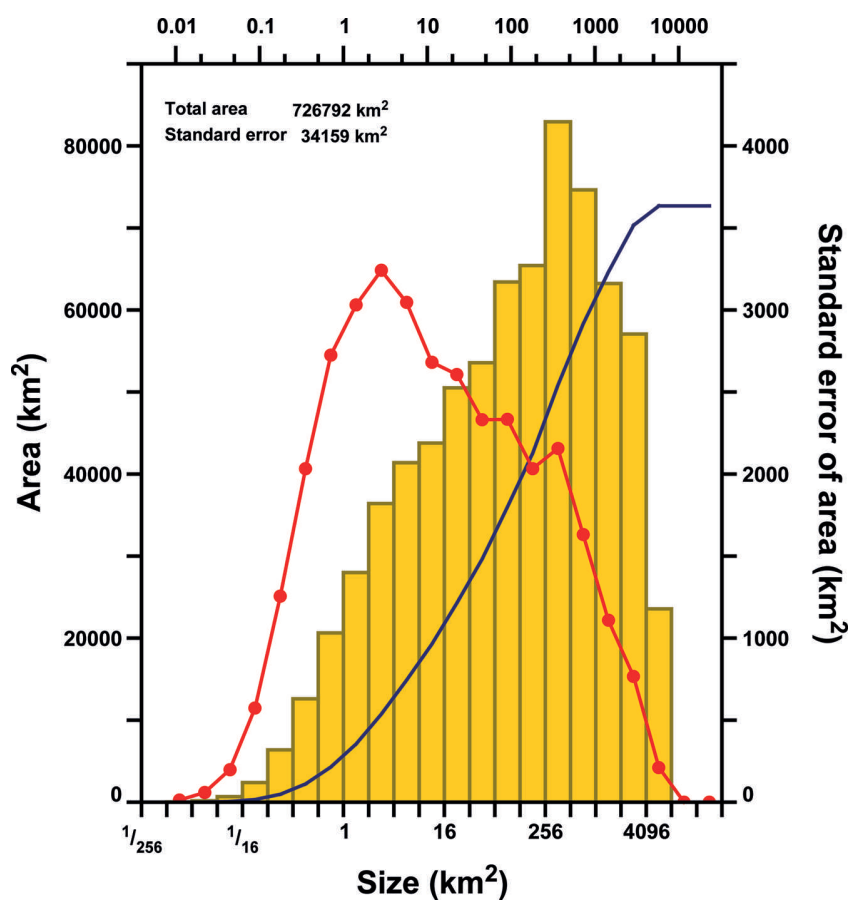

Fig. 6. Frequency distributions of glacier areas (histogram; left axis) and standard errors (connected dots; right axis). The continuous line shows the cumulative frequency distribution of areas (left axis, to be multiplied by 10).

The frequency distribution of glacier areas is shown in Figure 6. Acknowledging that some very small glaciers may be omitted by virtue of the imposition of minimum-area thresholds, it is nevertheless clear that the area distribution is dominated by large glaciers. Glaciers with areas between $\sim 4$ and $\sim 1500 \mathrm{~km}^{2}$ account for two-thirds of the ice cover.

The distribution of standard errors in Figure 6 is based on Eqn (1) with $k=3$ (Fig. 4). As follows from the form of Eqn (1) and the frequency distribution of the areas, smaller glaciers contribute more to the total uncertainty than do larger glaciers. In the smallest-size bin of Figure 6 the standard error of total bin area implied by Eqn (1) is $44 \%$, while in the largest-size bin it is $0.9 \%$. Of the uncertainty of $4.7 \%$ $\left(34000 \mathrm{~km}^{2}\right)$ in the total area, two-thirds is contributed by glaciers with areas between $\sim 1$ and $\sim 500 \mathrm{~km}^{2}$.

Figure 7 shows cumulative frequency distributions of glacier areas separated by first-order region. In seven regions the 50th percentile of the distribution (the 'median area') is smaller than $2 \mathrm{~km}^{2}$. The median area ranges upward to $181 \mathrm{~km}^{2}$ in Arctic Canada North, $351 \mathrm{~km}^{2}$ in Iceland and $706 \mathrm{~km}^{2}$ in Antarctica. In every region the mean area is con siderably less than the median area, reflecting the prominence of smaller glaciers in the size distribution of glacier numbers.

With the possible exceptions of Central Europe and the Antarctic and Subantarctic, the regional size distributions of glacier numbers (Fig. 8) exhibit a common pattern in which numbers increase steeply from the smallest-size class towards a maximum, typically between 0.25 and $1 \mathrm{~km}^{2}$. Beyond this inflection, numbers decrease at a rate that varies little from region to region, with a tendency to steepen towards the largest-size class.

The inflection is due, to an unknown extent, to underrecording of glacierets and other very small glaciers, whether because of the imposition of a minimum-area

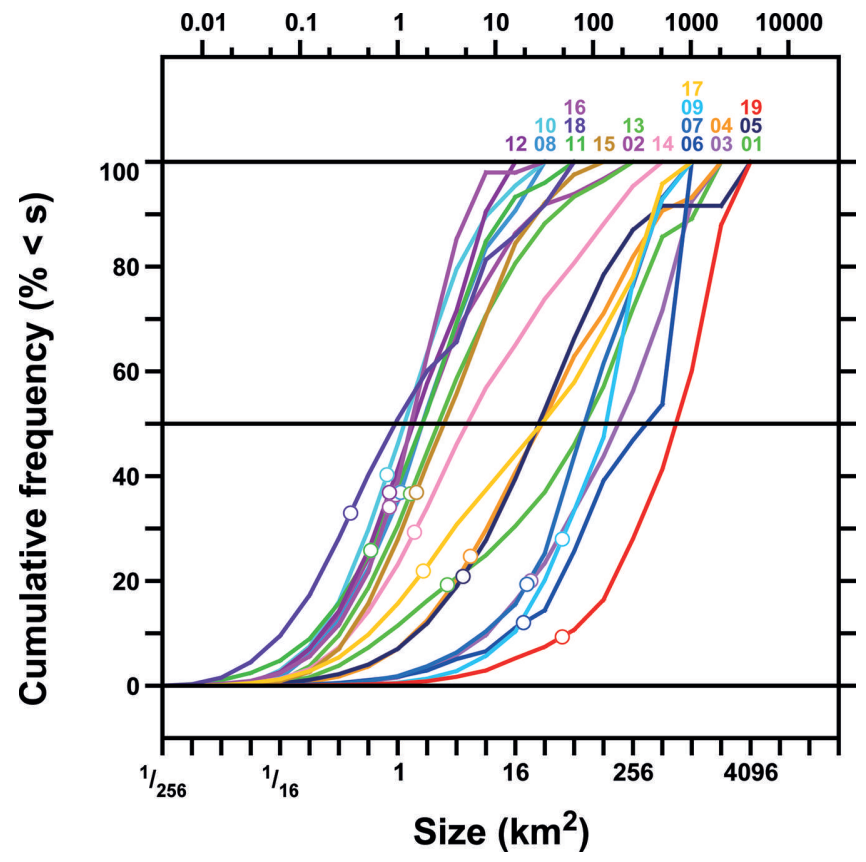

Fig. 7. Cumulative frequency distributions of glacier areas for the RGI regions. Coloured numerals: region numbers (see Table 2). Open circles: percentiles of the mean glacier areas. Region numbers: 01. Alaska; 02. Western Canada and US; 03. Arctic Canada North; 04. Arctic Canada South; 05. Greenland Periphery; 06. Iceland; 07. Svalbard; 08. Scandinavia; 09. Russian Arctic; 10. North Asia; 11. Central Europe; 12. Caucasus and Middle East; 13. Central Asia; 14. South Asia West; 15. South Asia East; 16. Low Latitudes; 17. Southern Andes; 18. New Zealand; 19. Antarctic and Subantarctic.

threshold, or coarse DEM resolution, or for other reasons. Over-recording, by systematic misidentification of small (as opposed to large) snowpatches, is also possible. If we neglect this possibility because we are unable to quantify it, a lower bound on the underestimate due to under-recording is obtained by assuming that the RGI always distinguishes correctly between glacierets and snowpatches: no glacierets are omitted, and the underestimate is zero. An upper bound can be obtained by assuming that inverse power-law scaling, as suggested by the form of the size-frequency curves at larger sizes (Fig. 8), continues in reality down to the smallest sizes. For each region (inset of Fig. 8) we extrapolate the line connecting the most numerous class and its next larger neighbour, and sum the quantity $s \times\left[n_{x}(s)-n_{\mathrm{RGI}}(s)\right]$ from the WGl minimum, $s_{\min }=0.01 \mathrm{~km}^{2}$, to $s_{x}$, the size of the most numerous class. Here $n_{x}(s)$ is the extrapolated estimate of the 'real' number and $n_{\mathrm{RGI}}(s)$ is the number of RGI glaciers of size $s$. The result is $10180 \mathrm{~km}^{2}$ if we sum the 19 extrapolates, and $7819 \mathrm{~km}^{2}$ if we sum the regional glacier numbers and repeat the calculation for the entire world. Thus the underestimate of global total area due to omission of glacierets appears to lie between zero and an upper bound of $1.1-1.4 \%$. The upper-bound calculations also imply a large increase in the total number of glaciers over that suggested in Section 4.1, to 462000 for the region-by-region calculation and to 435000 for the global calculation.

\subsection{Glacier hypsometry}

Among others (Huss and Farinotti, 2012; Marzeion and others, 2012), Radić and others (2014) have generated the hypsometry (area-altitude distribution) of each glacier from 


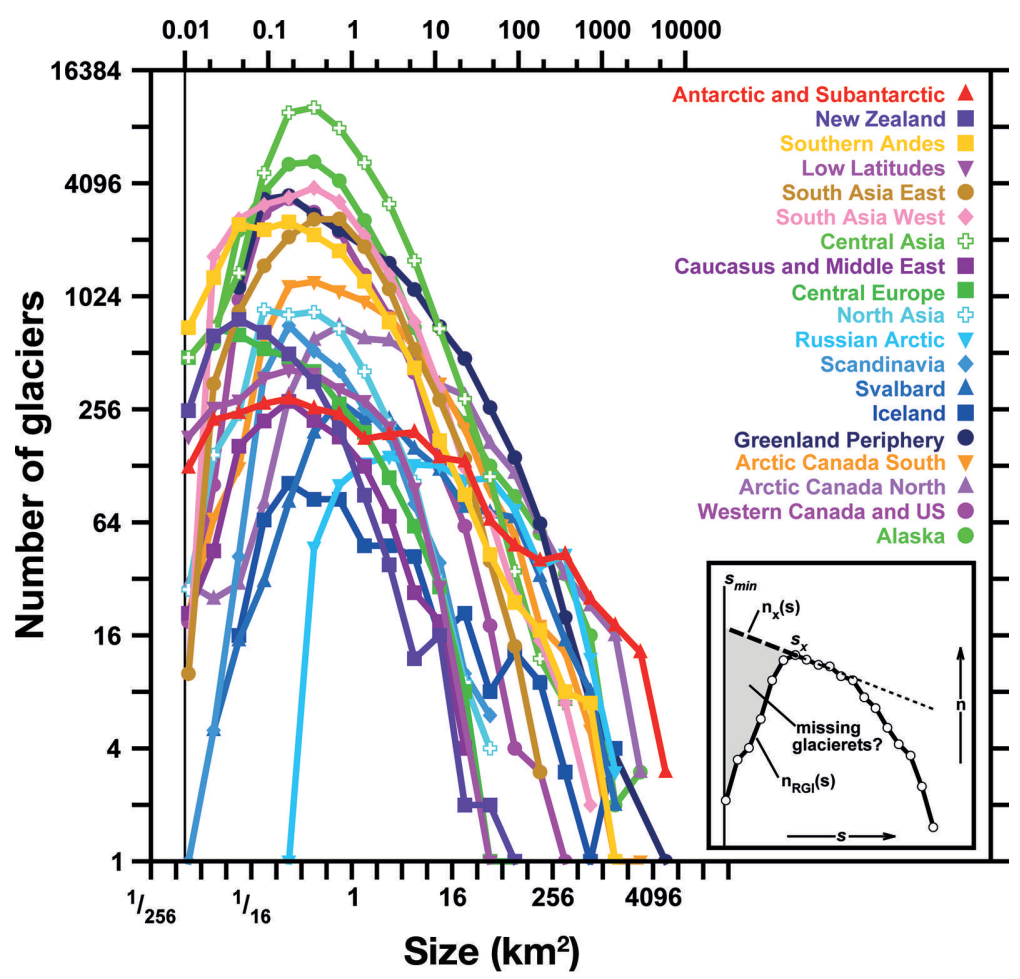

Fig. 8. Size distributions of the number of glaciers for the RGI regions. Inset: an illustration of the argument for an upper bound on the RGI area (represented by the shaded region) that is missing due to the omission of glacierets.

the RGI outlines and regional-scale DEMs. Figure 9a shows the total hypsometry of each region. Most of the world's glacier area is below $2000 \mathrm{~m}$, with comparatively little between $2500 \mathrm{~m}$ and $3500 \mathrm{~m}$, where only Central Europe and the Caucasus and Middle East have hypsometric modes. The mid- and low-latitude glaciers of Central Asia, South Asia East, South Asia West and the Low Latitudes have most of their area above $4000 \mathrm{~m}$. The spikes in the curves for Arctic Canada North, Arctic Canada South and Antarctica are DEM artefacts arising from poor interpolation from contour maps.

In Figure 9b, each glacier's elevation range is normalized from 0 to 100 (i.e. its minimum elevation is set to 0 and its maximum to 100) and its total area is normalized to be equal to 100. Then all glaciers in each region are averaged without weighting, resulting in a typical, size-independent hypsometric curve for the glaciers of the region. These normalized, regionally averaged hypsometries exhibit three characteristic patterns. In most regions, most glaciers have most of their area in the middle of their elevation ranges, with less on steep high-elevation slopes and in narrow lowelevation tongues. In the Antarctic and Subantarctic, the predominance of tidewater glaciers skews the curve to lower normalized elevations. In Arctic Canada North, Arctic Canada South, the Russian Arctic and Greenland, the typical hypsometry is skewed to higher normalized elevations by ice caps on high-elevation plateaus with relatively restricted low-elevation tongues.

\subsection{Glacier volume and mass}

Working with WGI-XF (Cogley, 2009a), Radić and Hock (2010) produced an upscaled estimate, $600 \pm 70 \mathrm{~mm} \mathrm{SLE}$ (sea-level equivalent), of global glacier volume including glaciers around the ice sheets. This estimate was obtained by volume-area scaling (Bahr and others, 1997). One estimate relying on RGI 1.0, and three on RGI 2.0, have appeared recently (Table 4). Radić and others (2014) reduced the earlier Radić-Hock estimate to $522 \mathrm{~mm} \mathrm{SLE}$. Most of the reduction was ascribed to the availability of the RGI, which made upscaling unnecessary. An alternative assumption about the prevalence of ice caps, used by Radić and others (2014) as part of their assessment of uncertainty, made the global total lower still, at $405 \mathrm{~mm} \mathrm{SLE}$. Marzeion and others (2012), working with RGI 1.0, modelled regional ice volumes by volume-area scaling, but because they excluded glaciers in Antarctica the global total suggested in Table 4 for their work, $468 \mathrm{mmSLE}$, is a rough estimate and is not independent of the three other estimates. Huss and Farinotti (2012) estimated a total of $423 \pm 57 \mathrm{mmSLE}$, based on a simple model of the glacier dynamics implied by the distribution of glacier surface elevations. Grinsted (2013), relying on a multivariate extension of volume-area scaling and on a different minimization criterion during calibration of the volume-area relationship, estimated a lesser total of $350 \pm 70 \mathrm{~mm}$ SLE.

The range of the estimates of total mass in Table 4 is 28\% of their average $(412 \mathrm{mmSLE})$. Explaining this spread is beyond the present scope, but some of the dispersion can be attributed to the rapid evolution of the RGI. For example, glaciers should not be aggregated for volume-area scaling, so glacier complexes, which were more numerous in RGl 1.0 and 2.0, dilute the accuracy of three of the estimates. Moreover, except in the Antarctic and Subantarctic, even RGI 3.2 offers no way to distinguish mountain and valley glaciers from ice caps. Volume-area scaling exponents for ice caps, whose thickness is large by comparison with the relief of their beds, are known to differ from those of mountain and valley glaciers (Bahr and others, 1997). The studies differed in their handling of this difference of scaling behaviour. The work of Huss and Farinotti may be less affected than the other three, although they noted that in 

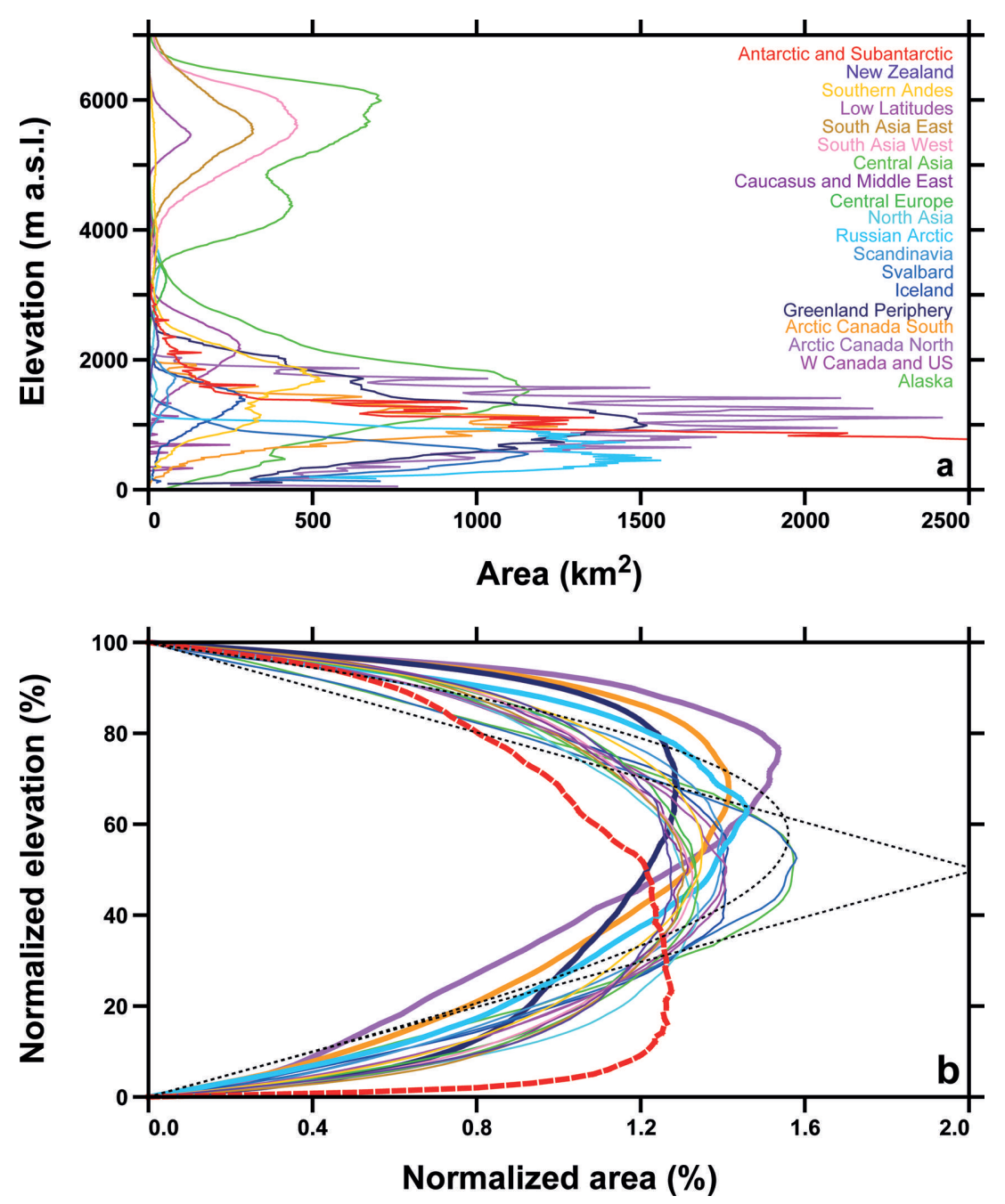

Fig. 9. Area-elevation distributions of the RGI regions. (a) Distribution of regional glacierized area with elevation. (b) Distribution of normalized glacierized area with normalized elevation, with the idealized approximations of Raper and Braithwaite (2006) drawn as dotted lines (triangle for mountain glaciers, representative curved line for ice caps); the normalizations are explained in the text. Arctic Canada North and South, Greenland and the Russian Arctic (thick solid curves), and the Antarctic and Subantarctic (thick dashed curve), are discussed in the text.

Arctic Canada South, where separate sets of outlines were available for glaciers and glacier complexes, the total volume obtained by modelling the glaciers was $7 \%$ less than that obtained by modelling the complexes.

Bahr and Radić (2012) show that, for some purposes, glaciers in the smallest size classes of a given sample can contain a significant fraction of the total volume of the sample. They suggest that, at the global scale, an accuracy in volume of $\pm 1 \%$ requires inclusion of all glaciers larger than $1 \mathrm{~km}^{2}$. At regional scales the threshold for a given desired accuracy depends on the size distribution. Where the largest glacier is of the order of $100 \mathrm{~km}^{2}$, total regional volume can only be estimated to $\pm 10 \%$ or better if the minimum-area threshold is $0.01 \mathrm{~km}^{2}$ or smaller. In some regions, therefore, more accurate estimates of volume will require more complete inventories of the smallest glaciers.

\subsection{Glacier climatology}

Figure 10, less detailed versions of which have appeared in Cogley (2012) and Huss and Farinotti (2012), illustrates how a complete inventory can add value to information from other sources. The figure summarizes a wealth of glacioclimatic information, showing for example that at any latitude glaciers with lower mid-range altitudes tend to be warmer or more 'maritime'. Maritime glaciers descend to lower altitudes than their more 'continental' counterparts, because more summer heat is required to remove the mass gained during their snowy winters. Conversely, continental glaciers tend to be dry and to persist only at higher, colder altitudes. Assuming that the mid-range altitude approximates the equilibrium-line altitude (which is not correct for tidewater glaciers), Figure 10 shows that the equilibrium line or snowline is not an isotherm: its temperature varies globally and at some single latitudes over a range of $\sim 20^{\circ} \mathrm{C}$.

Mernild and others (2013) extend the analysis shown in Figure 10. They use RGI glacier outlines to enable the modelling of Northern Hemisphere glacier freshwater balances driven by reanalysis data for annual time spans.

\subsection{Evolution of glacier mass balance}

Gardner and others (2013) used RGI 3.0 in the estimation of global average mass balance for 2003-09, a period for which estimates by interpolation of in situ measurements, satellite gravimetry and satellite laser altimetry are concurrently available. Results from in situ and remote-sensing methods differed significantly, but the RGI eliminated what 
Table 4. Glacier masses (Gt)* estimated with the RGI

Regional glacier mass

Region

Radić and others $(2014)^{\dagger+}$

Marzeion and others $(2012)^{\S}$

Huss and Farinotti $(2012)^{\dagger}$

Grinsted $(2013)^{\dagger}$

01 Alaska
02 Western Canada and US
03 Arctic Canada North
04 Arctic Canada South
05 Greenland Periphery
06 Iceland
07 Svalbard and Jan Mayen
08 Scandinavia
09 Russian Arctic
10 North Asia
11 Central Europe
12 Caucasus and Middle East
13 Central Asia
14 South Asia West
15 South Asia East
16 Low Latitudes
17 Southern Andes
18 New Zealand
19 Antarctic and Subantarctic

Total (Gt)

Total ( $m$ m SLE)

$\begin{array}{cc}16736 & 28021 \pm 2465 \\ 1148 & 1124 \pm 72 \\ 31244 & 37555 \pm 4858 \\ 6295 & 7540 \pm 544 \\ 12229 & 10005 \pm 1595 \\ 2390 & 4640 \pm 1595 \\ 6119 & 8011 \pm 580 \\ 182 & 218 \\ 11016 & 21315 \pm 3625 \\ 247 & 218 \pm 36 \\ 125 & 109 \\ 61 & 72 \\ 5465 & 5655 \pm 109 \\ 3413 & 3444 \pm 218 \\ 1623 & 1378 \pm 36 \\ 208 & 218 \\ 4606 & 4640 \pm 145 \\ 71 & 72 \\ 43772 & - \\ \mathbf{1 4 6 9 4 9} & (\mathbf{1 6 9 1 8 5})^{\S} \\ 405 & (468)^{\S}\end{array}$

$18379 \pm 1341$
$906 \pm 72$
$30958 \pm 4241$
$8845 \pm 1015$
$17146 \pm 2392$
$3988 \pm 326$
$8700 \pm 834$
217
$15152 \pm 1994$
109
109
72
$4531 \pm 435$
$2900 \pm 254$
$1196 \pm 109$
145
$6018 \pm 471$
72
$33749 \pm 7576$
$\mathbf{1 5 3} \mathbf{1 9 2} \pm \mathbf{2 0 6 9 9}$
$423 \pm 57$

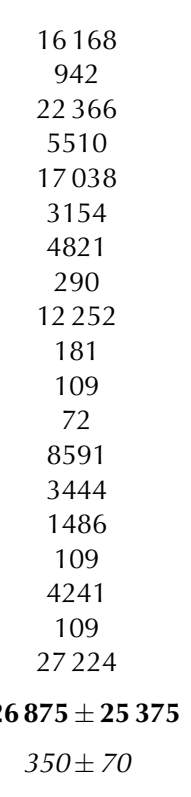

\footnotetext{
*1 Gt is $1.0 / 362.5 \mathrm{~mm} \mathrm{SLE}, 1.0 \mathrm{~km}^{3}$ w.e. and (assuming a density of $900 \mathrm{~kg} \mathrm{~m}^{-3}$ for the glacier) $1.11 \ldots \mathrm{km}^{3}$ ice equivalent.

†sing RGI 2.0 .

Their quantity $V^{*}$.

§Using RGI 1.0. Modelled for a nominal date of 2009 , and adjusted here by taking the area of the ocean to be $362.5 \times 10^{6} \mathrm{~km}^{2}$. Ice in region $19 \mathrm{was}$ not modelled and the entries in the Total rows have been augmented by the average of the three region-19 estimates.
}

was formerly the primary source of such differences, namely the previously differing estimates of regional glacier extent.

Giesen and Oerlemans (2013) used RGI 1.0 to scale single-glacier mass-balance projections up to global scale over the 21 st century, while Hirabayashi and others (2013) used information derived from RGI 1.0 to simulate worldwide climatic mass balance from 1948 to 2099. Marzeion and others (2012) and Radić and others (2014) have published more detailed mass-balance modelling studies applied to each single RGI glacier, from versions 1.0 and 2.0 respectively. In each case the role of the RGI outline was to make possible the initialization of glacier area and hence volume, and the extraction of topography from a DEM. Both studies relied on the RGI regions as a standardized way to present geographical variations. Both were obliged to do their own subdivision of glacier complexes, and to generate topographic information by overlaying RGI outlines on DEMs. Marzeion and others, lacking dates for the outlines of RGI 1.0, had to supply them by intelligent guesswork. Radić and others accepted RGI 2.0, which has better but still incomplete date coverage, as a representation of 'presentday' glaciers. No global compilation of rates of area change is available, and it is therefore not yet possible to interpolate measured areas, even when their dates are known, to any particular reference date.

\section{SUMMARY AND OUTLOOK}

The Randolph Glacier Inventory, a cooperative effort of the community of glaciologists, is a globally complete compilation of digital vector outlines of the world's glaciers other than the ice sheets. It contains outlines of nearly 200000 glaciers. Allowing for currently omitted glacierets the total number of glaciers could be greater, easily exceeding 400000 , but the missing glacierets represent $1.4 \%$ or less of the recorded glacierized area, and possibly much less. The total glacierized area is estimated as $726800 \pm$ $34000 \mathrm{~km}^{2}$, although a number of questions remain about how best to calculate the uncertainty of this total. The area of glaciers on islands surrounding the Antarctic mainland is $132900 \pm 2520 \mathrm{~km}^{2}$ and the area of Greenland glaciers other than the ice sheet is $89700 \pm 4490 \mathrm{~km}^{2}$; the remaining glacierized regions contribute $504200 \pm 27000 \mathrm{~km}^{2}$ to the total.

The RGI is a much richer product than the national lists envisaged half a century ago (Section 1.1), but is nevertheless a work in progress. Outstanding tasks include:

Improving the quality of outlines where recent regional inventories are likely to be more accurate. For example, recent work at the International Centre for Integrated Mountain Development, Kathmandu, Nepal (Bajracharya and Shrestha, 2011), and in China, is known to have better georeferencing and accuracy than RGI 3.2.

Providing outlines for $\sim 3000$ glaciers, mostly in North Asia, for which only location and area are known at present.

Shortening the time span of coverage. Of the outlines with dates, $\sim 8 \%$ pre-date 1999 .

Replacing date ranges with dates and supplying dates that are missing. Sometimes multiple images for a particular glacier make a range necessary, but many sources provide information in a form not readily converted to explicit dates. 


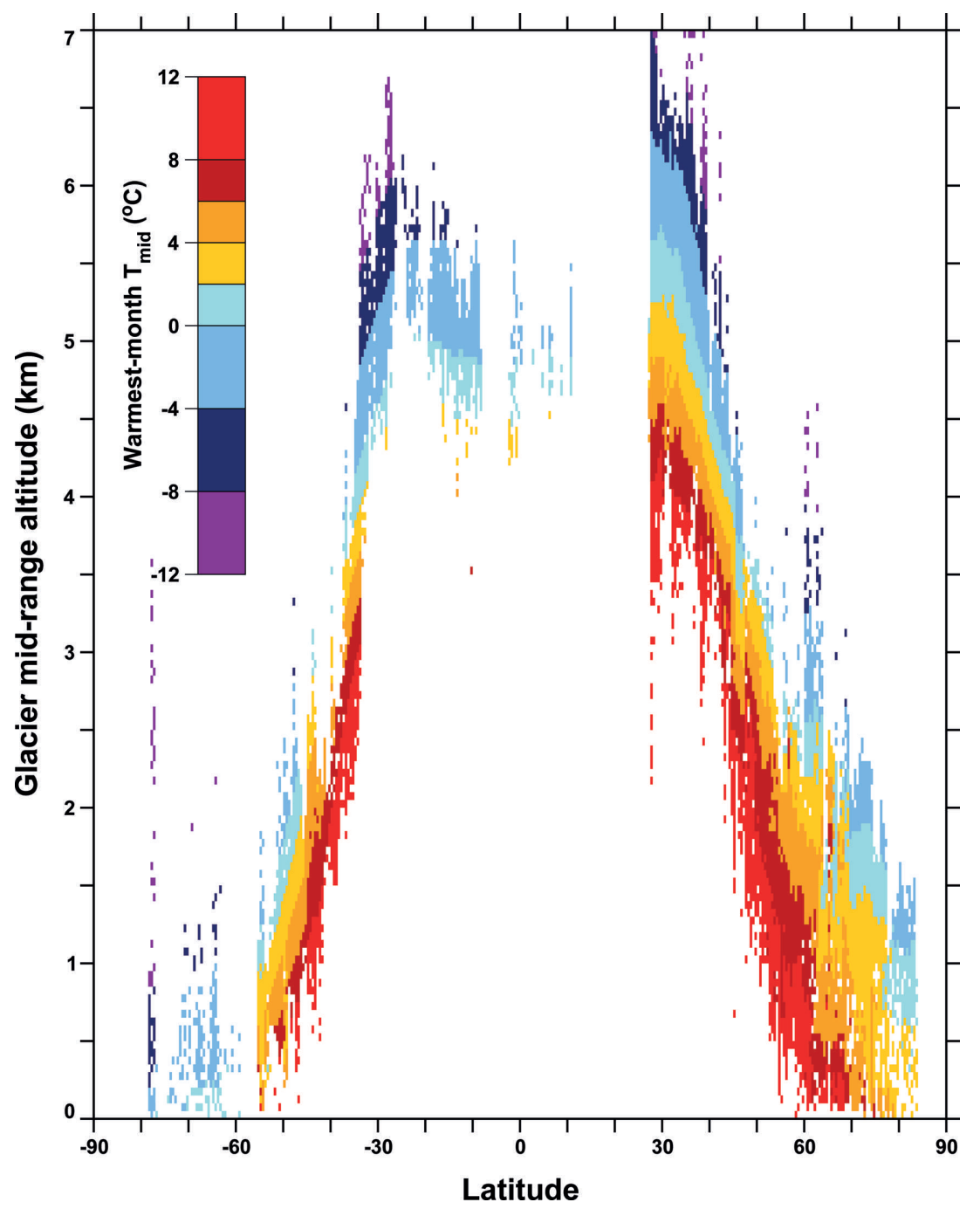

Fig. 10. Zonal averages of the mean temperature of the warmest month at the glacier mid-range altitude (the average of the minimum and maximum glacier altitude). RGI glaciers with minimum altitudes of zero, assumed to be tidewater glaciers, were discarded. The mid-range altitude of each remaining glacier was estimated by overlaying its outline on a suitable DEM (see Radić and others, 2014, for details). The altitudes were averaged firstly into cells of size $50 \mathrm{~m} \times 0.5^{\circ} \times 0.5^{\circ}$ and then over longitude. Temperatures are warmest-month free-air temperatures interpolated from the US National Centers for Environmental Prediction (NCEP)/National Center for Atmospheric Research (NCAR) Reanalysis (Kalnay and others, 1996).

Distinguishing between land-terminating and laketerminating glaciers. So far, lake-terminating glaciers have been identified as such in only three regions.

Adding outlines of the debris-covered parts of glaciers.

Adding information about topography and hypsometry. Given the importance of early availability, it was decided not to try to include this information in the RGI. Several investigators have already exploited the RGI to retrieve detail from DEMs, but a standardized product (Paul and others, 2009b) of acknowledged uniform quality would reduce uncertainty arising from the use of different topographic sources, and would allow ice caps to be identified by examination of longitudinal profiles of surface elevation.

Documenting more completely the data sources and the methods used to delineate glaciers.

Merging the RGI into GLIMS. This is an organizational matter requiring forethought.
The RGI was not designed for the measurement of rates of glacier area change, for which the greatest possible accuracies in dating, delineation and georeferencing are essential. Many RGI outlines pass this test, but in general completeness of coverage had higher priority. Rather, the strength of the RGI lies in the capacity it offers for handling many glaciers at once (e.g. for estimating glacier volumes and rates of elevation change at regional and global scales and for simulating cryospheric responses to climatic forcing).

Finally, much remains to be done in the investigation of uncertainty. Our error model (Eqn (1)) incorporates some understanding of the sources of uncertainty, but does not address the non-normality of the errors arising from the diversity of information sources and methods of analysis. Further, the problem of uncertainty in glacier volume, at all scales from the single glacier to the world, is intractable. Measurements of volume are few, and understanding of the relationships between volume and the observable quantities is limited. Nevertheless uncertainty in glacier volume is a problem of wider significance than uncertainty in glacier area, and deserves continued attention. 


\section{ACKNOWLEDGEMENTS}

We thank D. Bahr for helpful discussions, and an anonymous reviewer for a constructive review. Support for planning of the RGI, and for meetings in Winter Park, Colorado, and Randolph, New Hampshire, USA, was provided by the International Association for Cryospheric Sciences and the International Arctic Science Committee. K.M. Cuffey kindly provided the venue and helped to arrange a meeting in Berkeley, California, USA. We are grateful for support from NASA's Cryospheric Research Branch (grants NNX11AF41G to C.K., NNX13AK37G to A.A. and J.R., NNX11AO23G to A.B.); the US Geological Survey's Alaska Climate Science Center and the US National Park Service (grant H9911080028 to A.A. and J.R.); the European Space Agency (Glaciers_cci project 4000101778/ 10/I-AM to T.B. and F.P.); the ice2sea programme (European Union 7th Framework Programme grant No. 226375 to P.R.; ice2sea contribution No. 100); the German Research Foundation (DFG, grant BO 3199/2-1 to T.B.); the US National Science Foundation (grants ANT1043649 and EAR 0943742 to R.H.); the Austrian Science Fund (FWF; grants I900-N21 and P25362-N26 to G.K.); and the Natural Sciences and Engineering Research Council of Canada (Discovery Grant) and Environment Canada (to M.S.).

\section{REFERENCES}

ADD Consortium (2000) Antarctic Digital Database, Version 3.0, Database, Manual and Bibliography. Version 4.1, digital data. Scientific Committee on Antarctic Research, Cambridge

Arendt A and 77 others (2013) Randolph Glacier Inventory [v3.2]: a dataset of global glacier outlines. Global Land Ice Measurements from Space, Boulder, CO. Digital media: http://www.glims.org/ $\mathrm{RGl} / \mathrm{randolph} . \mathrm{html}$

Bahr DB and Radić V (2012) Significant contribution to total mass from very small glaciers. Cryosphere, 6(4), 763-770 (doi: 10.5194/tc-6-763-2012)

Bahr DB, Meier MF and Peckham SD (1997) The physical basis of glacier volume-area scaling. J. Geophys. Res., 102(B9), 20355-20362 (doi: 10.1029/97JB01696)

Bahr DB, Dyurgerov M and Meier MF (2009) Sea-level rise from glaciers and ice caps: a lower bound. Geophys. Res. Lett., 36(3), L03501 (doi: 10.1029/2008GL036309)

Bajracharya SR and Shrestha B eds (2011) The status of glaciers in the Hindu Kush-Himalayan region. International Centre for Integrated Mountain Development, Kathmandu

Bedford D and Haggerty C (1996) New digitized glacier inventory for the former Soviet Union and China. Earth Syst. Monitor, 6(3), 8-10

Berthier E, Schiefer E, Clarke GKC, Menounos B and Rémy F (2010) Contribution of Alaskan glaciers to sea-level rise derived from satellite imagery. Nature Geosci., 3(2), 92-95 (doi: 10.1038/ ngeo737)

Bhambri R and Bolch T (2009) Glacier mapping: a review with special reference to the Indian Himalayas. Progr. Phys. Geogr., 33(5), 672-704 (doi: 10.1177/0309133309348112)

Bliss A, Hock R and Cogley JG (2013) A new inventory of mountain glaciers and ice caps for the Antarctic periphery. Ann. Glaciol., 54(63 Pt 2), 191-199 (doi: 10.3189/2013AoG63A377)

Bolch T, Menounos B and Wheate R (2010) Landsat-based inventory of glaciers in western Canada, 1985-2005. Remote Sens. Environ., 114(1), 127-137 (doi: 10.1016/j.rse.2009.08.015)

Burgess EW, Forster RR and Larsen CF (2013) Flow velocities of Alaskan glaciers. Nature Commun., 4, 2146 (doi: 10.1038/ ncomms3146)

Casey A (2003) Papers and recommendations: Snow Watch 2002 Workshop and Workshop on Assessing Global Glacier
Recession. (Glaciological Data GD-32) National Snow and Ice Data Center and World Data Center A for Glaciology, Boulder, $\mathrm{CO}$

Cogley JG (2003) GGHYDRO: Global Hydrographic Data, Release 2.3. (Trent Technical Note 2003-1) Department of Geography, Trent University, Peterborough, Ont. http://people.trentu.ca/ qcogley/glaciology/gghrls231.pdf

Cogley JG (2009a) A more complete version of the World Glacier Inventory. Ann. Glaciol., 50(53), 32-38 (doi: 10.3189/ 172756410790595859)

Cogley JG (2009b) Geodetic and direct mass-balance measurements: comparison and joint analysis. Ann. Glaciol., 50(50), 96-100 (doi: 10.3189/172756409787769744)

Cogley JG (2012) The future of the world's glaciers. In HendersonSellers A and McGuffie K eds. The future of the world's climate. Elsevier, Waltham, MA, 197-222

Danko DM (1992) The Digital Chart of the World project. Photogramm. Eng. Remote Sens., 58(8), 1125-1128

Dyurgerov MB and Meier MF (2005) Glaciers and the changing Earth system: a 2004 snapshot. (INSTAAR Occasional Paper 58) Institute of Arctic and Alpine Research, University of Colorado, Boulder, $\mathrm{CO}$

Farinotti D, Huss M, Bauder A, Funk M and Truffer M (2009) A method to estimate ice volume and ice-thickness distribution of alpine glaciers. J. Glaciol., 55(191), 422-430 (doi: 10.3189/ 002214309788816759)

Frey $\mathrm{H}$ and Paul F (2012) On the suitability of the SRTM DEM and ASTER GDEM for the compilation of topographic parameters in glacier inventories. Int. J. Appl. Earth Obs. Geoinf., 18, 480-490 (doi: 10.1016/j.jag.2011.09.020)

Gardelle J, Berthier E, Arnaud Y and Kääb A (2013) Region-wide glacier mass balances over the Pamir-Karakoram-Himalaya during 1999-2011. Cryosphere, 7(4), 1263-1286 (doi: 10.5194/ tc-7-1263-2013)

Gardner AS and 8 others (2011) Sharply increased mass loss from glaciers and ice caps in the Canadian Arctic Archipelago. Nature, 473(7347), 357-360 (doi: 10.1038/nature10089)

Gardner AS and 15 others (2013) A reconciled estimate of glacier contributions to sea level rise: 2003 to 2009. Science, 340(6134), 852-857 (doi: 10.1126/science.1234532)

Giesen RH and Oerlemans J (2013) Climate-model induced differences in the 21 st century global and regional glacier contributions to sea-level rise. Climate Dyn., 41(11-12), 3283-3300 (doi: 10.1007/s00382-013-1743-7)

Gregory JM and Oerlemans J (1998) Simulated future sea-level rise due to glacier melt based on regionally and seasonally resolved temperature changes. Nature, 391(6666), 474-476 (doi: 10.1038/35119)

Grinsted A (2013) An estimate of global glacier volume. Cryosphere, 7(1), 141-151 (doi: 10.5194/tc-7-141-2013)

Hirabayashi Y, Zang Y, Watanabe S, Koirala S and Kanae S (2013) Projection of glacier mass changes under a high-emission climate scenario using the global glacier model HYOGA2. Hydrol. Res. Lett., 7(1), 6-11 (doi: 10.3178/hrl.7.6)

Hock R, De Woul M, Radić V and Dyurgerov M (2009) Mountain glaciers and ice caps around Antarctica make a large sea-level rise contribution. Geophys. Res. Lett., 36(7), L07501 (doi: 10.1029/2008GL037020)

Howat IM, Negrete A and Smith BE (2014) The Grenland Ice Mapping Project (GIMP) land classification and surface elevation datasets. Cryos. Discuss., 8(1), 1-26 (doi: 10.5194/tcd-8-1-2014)

Huss M and Farinotti D (2012) Distributed ice thickness and volume of all glaciers around the globe. J. Geophys. Res., 117(F4), F04010 (doi: 10.1029/2012JF002523)

Kalnay E and 21 others (1996) The NCEP/NCAR 40-year reanalysis project. Bull. Am. Meteorol. Soc., 77(3), 437-471 (doi: 10.1175/ 1520-0477(1996)077<0437:TNYRP > 2.0.CO;2)

Kargel JS, Leonard G), Bishop MP, Kääb A and Raup B eds. (in press) Global Land Ice Measurements from Space. Springer Praxis, Chichester 
Kienholz C, Hock R and Arendt A (2013) A new semi-automatic approach for dividing glacier complexes into individual glaciers. J. Glaciol., 59(217), 925-937 (doi: 10.3189/2013JoG12J138)

Le Bris R, Paul F, Frey H and Bolch T (2011) A new satellite-derived glacier inventory for western Alaska. Ann. Glaciol., 52(59), 135-143 (doi: 10.3189/172756411799096303)

Linsbauer A, Paul F and Haeberli W (2012) Modeling glacier thickness distribution and bed topography over entire mountain ranges with GlabTop: application of a fast and robust approach. J. Geophys. Res., 117(F3), F03007 (doi: 10.1029/2011JF002313)

Markham BL, Storey JC, Williams DL and Irons JR (2004) Landsat sensor performance: history and current status. IEEE Trans. Geosci. Remote Sens., 42(12), 2691-2694 (doi: 10.1109/ TGRS.2004.840720)

Marzeion B, Jarosch AH and Hofer M (2012) Past and future sealevel change from the surface mass balance of glaciers. Cryosphere, 6(6), 1295-1322 (doi: 10.5194/tc-6-1295-2012)

Meier MF and Bahr DB (1996) Counting glaciers: use of scaling methods to estimate the number and size distribution of glaciers of the world. CRREL Spec. Rep. 96-27, 89-94

Mernild SH, Liston GE and Hiemstra CA (2013) Individual and regional glacier and ice cap surface mass balance and runoff modeling for the Northern Hemisphere. Geophys. Res. Abstr., 15, EGU2013-02900

Nuth C and 7 others (2013) Decadal changes from a multi-temporal glacier inventory of Svalbard. Cryos. Discuss., 7(3), 2489-2532 (doi: 10.5194/tcd-7-2489-2013)

Ohmura A (2004) Cryosphere during the twentieth century. In Sparling JY and Hawkesworth CJ eds. The state of the planet: frontiers and challenges in geophysics. American Geophysical Union, Washington DC, 239-257

Ohmura A (2009) Completing the World Glacier Inventory. Ann. Glaciol., 50(53), 144-148 (doi: 10.3189/172756410790595840)

Paul F, Kääb A, Rott H, Shepherd A, Strozzi T and Volden E (2009a) GlobGlacier: a new ESA project to map the world's glaciers and ice caps from space. EARSeL eProc., 8(1), 11-25

Paul F and 18 others (2009b) Recommendations for the compilation of glacier inventory data from digital sources. Ann. Glaciol., 50(53), 119-126 (doi: 10.3189/172756410790595778)

Paul F, Bolch T, Kääb A, Nagler T, Shepherd A and Strozzi T (2012) Satellite-based glacier monitoring in the ESA project Glaciers_cci. In Proceedings of the International Geoscience and Remote Sensing Symposium (IGARSS), 23-27 July 2012, Munich, Germany. Institute of Electrical and Electronics Engineers, Piscataway, NJ, 3222-3225

Paul F and 18 others (2013) On the accuracy of glacier outlines derived from remote-sensing data. Ann. Glaciol., 54(63 Pt 1), 171-182 (doi: 10.3189/2013AoG63A296)
Radić V and Hock R (2010) Regional and global volumes of glaciers derived from statistical upscaling of glacier inventory data. J. Geophys. Res., 115(F1), F01010 (doi: 10.1029/ 2009JF001373)

Radić V, Bliss A, Beedlow AC, Hock R, Miles E and Cogley JG (2014) Regional and global projections of twenty-first century glacier mass changes in response to climate scenarios from global climate models. Climate Dyn., 42(1-2), 37-58 (doi: 10.1007/s00382-013-1719-7)

Raper SCB and Braithwaite RJ (2005) The potential for sea level rise: new estimates from glacier and ice cap area and volume distributions. Geophys. Res. Lett., 32(5), L05502 (doi: 10.1029/ 2004GL021981)

Raper SCB and Braithwaite RJ (2006) Low sea level rise projections from mountain glaciers and icecaps under global warming. Nature, 439(7074), 311-313 (doi: 10.1038/nature04448)

Rastner P, Bolch T, Mölg N, Machguth H, Le Bris R and Paul F (2012) The first complete inventory of the local glaciers and ice caps on Greenland. Cryosphere, 6(6), 1483-1495 (doi: 10.5194/ tc-6-1483-2012)

Raup B and Khalsa SJS (2007) GLIMS analysis tutorial. http://www. glims.org/MapsAndDocs/assets/GLIMS_Analysis_Tutorial_a4.pdf

Raup B and 11 others (2007) Remote sensing and GIS technology in the Global Land Ice Measurements from Space (GLIMS) Project. Comput. Geosci., 33(1), 104-125 (doi: 10.1016/ j.cageo.2006.05.015)

Raup B, Arendt A, Armstrong R, Barrett A, Khalsa SJS and Racoviteanu A (2013) GLIMS and the RGI: relationships present and future. Geophys. Res. Abstr., 15, EGU2013-11831

Schiefer E, Menounos B and Wheate R (2008) An inventory and morphometric analysis of British Columbia glaciers, Canada. J. Glaciol., 54(186), 551-560 (doi: 10.3189/ 002214308785836995)

Sedov RV (1997) Ledniki Chukotki [Glaciers of Chukotka]. Mater. Glyatsiol. Issled. 82, 213-217 [in Russian with English summary]

World Glacier Monitoring Service (WGMS) (1989) World glacier inventory: status 1988, ed. Haeberli W, Bösch H, Scherler K, Østrem G, and Wallén CC. IAHS(ICSI)-UNEP-UNESCO, World Glacier Monitoring Service, Zürich

World Meteorological Organization (WMO) (2004) Implementation plan for the Global Observing System for climate in support of the UNFCCC. (WMO/TD No. 1219) World Meteorological Organization, Geneva

Wulder MA, Masek JG, Cohen WB, Loveland TR and Woodcock CE (2012) Opening the archive: how free data has enabled the science and monitoring promise of Landsat. Remote Sens. Environ., 122, 2-10 (doi: 10.1016/j.rse.2012.01.010)

\section{APPENDIX}

\section{Members of the Randolph Consortium}

L.M. Andreassen, ${ }^{1}$ S. Bajracharya, ${ }^{2}$ N.E. Barrand, ${ }^{3}$ M.J. Beedle, ${ }^{4}$ E. Berthier, ${ }^{5}$ R. Bhambri, ${ }^{6}$ I. Brown, ${ }^{7}$ D.O. Burgess, ${ }^{8}$ E.W. Burgess, ${ }^{9}$ F. Cawkwell, ${ }^{10}$ T. Chinn, ${ }^{11}$ L. Copland, ${ }^{12}$ N.J. Cullen, ${ }^{13}$ B. Davies, ${ }^{14}$ H. De Angelis, ${ }^{7}$ A.G. Fountain, ${ }^{15}$ H. Frey, ${ }^{16}$ B.A. Giffen, ${ }^{17}$ N.F. Glasser, ${ }^{14}$ S.D. Gurney, ${ }^{18}$ W. Hagg, ${ }^{19}$ D.K. Hall, ${ }^{20}$ U.K. Haritashya, ${ }^{21}$ G. Hartmann, ${ }^{22}$ S. Herreid ${ }^{9}{ }^{\text {I. Howat, }}{ }^{23}$ H. Jiskoot, ${ }^{24}$ T.E. Khromova, ${ }^{25}$ A. Klein, ${ }^{26}$ J. Kohler, $^{27}$ M. König, ${ }^{27}$ D. Kriegel, ${ }^{28}$ S. Kutuzov, ${ }^{25}$ I. Lavrentiev, ${ }^{25}$ R. Le Bris, ${ }^{16}$ X. Li, ${ }^{29}$ W.F. Manley, ${ }^{30}$ C. Mayer, ${ }^{31}$ B. Menounos, ${ }^{32}$ A. Mercer, ${ }^{7}$ P. Mool, ${ }^{2}$ A. Negrete, ${ }^{23}$ G. Nosenko, ${ }^{25}$ C. Nuth, ${ }^{33}$ A. Osmonov, ${ }^{34}$ R. Pettersson, ${ }^{35}$ A. Racoviteanu, ${ }^{36}$ R. Ranzi, ${ }^{37}$ M.A. Sarıkaya, ${ }^{38}$ C. Schneider, ${ }^{39}$ O. Sigurðsson, ${ }^{40}$ P. Sirguey, ${ }^{13}$ C.R. Stokes, ${ }^{41}$ R. Wheate, ${ }^{32}$ G.J. Wolken, ${ }^{42}$ L.Z. Wu, ${ }^{29}$ F.R. Wyatt ${ }^{43}$

\section{${ }^{1}$ Norwegian Water Resources and Energy Directorate, Oslo, Norway}

${ }^{2}$ International Centre for Integrated Mountain Development, Kathmandu, Nepal

${ }^{3}$ University of Birmingham, Birmingham, UK

${ }^{4}$ University of Northern British Columbia, Terrace, British Columbia, Canada

${ }^{5}$ Laboratoire d'Etudes en Géophysique et Océanographie Spatiales, Toulouse, France

${ }^{6}$ Wadia Institute of Himalayan Geology, Dehradun, India

${ }^{7}$ Stockholm University, Stockholm, Sweden

${ }^{8}$ Geological Survey of Canada, Ottawa, Ontario, Canada 
${ }^{9}$ University of Alaska Fairbanks, Fairbanks, AK, USA

${ }^{10}$ University College Cork, Cork, Ireland

${ }^{11}$ National Institute of Water and Atmospheric Research, Dunedin, New Zealand

${ }^{12}$ University of Ottawa, Ottawa, Ontario, Canada

${ }^{13}$ University of Otago, Dunedin, New Zealand

${ }^{14}$ University of Aberystwyth, Aberystwyth, UK

${ }^{15}$ Portland State University, Portland, OR, USA

${ }^{16}$ University of Zürich, Zürich, Switzerland

${ }^{17}$ National Park Service, Anchorage, AK, USA

${ }^{18}$ University of Reading, Reading, UK

${ }^{19}$ Ludwig Maximilians University, Munich, Germany

${ }^{20}$ Goddard Space Flight Center, Greenbelt, MD, USA

${ }^{21}$ University of Dayton, Dayton, OH, USA

${ }^{22}$ Alberta Geological Survey, Edmonton, Alberta, Canada

${ }^{23}$ The Ohio State University, Columbus, OH, USA

${ }^{24}$ University of Lethbridge, Lethbridge, Alberta, Canada

${ }^{25}$ Institute of Geography, Russian Academy of Sciences, Moscow, Russia

${ }^{26}$ Texas A\&M University, College Station, TX, USA

${ }^{27}$ Norwegian Polar Institute, Tromsø, Norway

${ }^{28}$ German Research Centre for Geosciences, Potsdam, Germany

${ }^{29}$ Cold and Arid Regions Environmental and Engineering Research Institute, Lanzhou, China

${ }^{30}$ University of Colorado, Boulder, CO, USA

${ }^{31}$ Commission for Geodesy and Glaciology, Bavarian Academy of Sciences, Munich, Germany

${ }^{32}$ University of Northern British Columbia, Prince George, British Columbia, Canada

${ }^{33}$ University of Oslo, Oslo, Norway

${ }^{34}$ Central Asian Institute of Applied Geosciences, Bishkek, Kyrgyzstan

${ }^{35}$ University of Uppsala, Uppsala, Sweden

${ }^{36}$ Laboratoire de Glaciologie et Géophysique de l'Environnement, Grenoble, France

${ }^{37}$ University of Brescia, Brescia, Italy

${ }^{38}$ Fatih University, Istanbul, Turkey

${ }^{39}$ RWTH Aachen University, Aachen, Germany

${ }^{40}$ Icelandic Meteorological Office, Reykjavík, Iceland

${ }^{41}$ Durham University, Durham, UK

${ }^{42}$ Alaska Division of Geological and Geophysical Surveys, Fairbanks, AK, USA

${ }^{43}$ University of Alberta, Edmonton, Alberta, Canada

MS received 6 September 2013 and accepted in revised form 26 January 2014 